\title{
Hyperexcitability and Loss of Feedforward Inhibition Contribute to Aberrant Plasticity in the Fmr1KO Amygdala
}

\author{
(D)Matthew N. Svalina, ${ }^{1,2,3,4, *}$ E. Mae Guthman, ${ }^{1,2, *}$ Christian A. Cea-Del Rio, ${ }^{2,5}$ J. Keenan Kushner, ${ }^{1,2}$ \\ Serapio M. Baca, ${ }^{2}$ Diego Restrepo, ${ }^{1,4, \#}$ and Molly M. Huntsman, ${ }^{1,2,6, \#}$
}

https://doi.org/10.1523/ENEURO.0113-21.2021

\begin{abstract}
${ }^{1}$ Neuroscience Graduate Program, University of Colorado Anschutz Medical Campus, Aurora, CO 80045, ${ }^{2}$ Department of Pharmaceutical Sciences, Skaggs School of Pharmacy and Pharmaceutical Sciences, University of Colorado Anschutz Medical Campus, Aurora, CO 80045, ${ }^{3}$ Medical Scientist Training Program, University of Colorado Anschutz Medical Campus, Aurora, CO 80045, ${ }^{4}$ Department of Cell and Developmental Biology, University of Colorado Anschutz Medical Campus, Aurora, CO 80045, ${ }^{5}$ Centro de Investigación Biomédica y Aplicada, Escuela de Medicina, Facultad de Ciencias Médicas, Universidad de Santiago de Chile, Santiago 9160000, Chile, and ${ }^{6}$ Department of Pediatrics, School of Medicine, University of Colorado Anschutz Medical Campus, Aurora, CO 80045
\end{abstract}

\begin{abstract}
Fragile $X$ syndrome (FXS) is a neurodevelopmental disorder (NDD) characterized by intellectual disability, autism spectrum disorders (ASDs), and anxiety disorders. The disruption in the function of the FMR1 gene results in a range of alterations in cellular and synaptic function. Previous studies have identified dynamic alterations in inhibitory neurotransmission in early postnatal development in the amygdala of the mouse model of FXS. However, little is known about how these changes alter microcircuit development and plasticity in the lateral amygdala (LA). Using whole-cell patch clamp electrophysiology, we demonstrate that principal neurons (PNs) in the LA exhibit hyperexcitability with a concomitant increase in the synaptic strength of excitatory synapses in the BLA. Further, reduced feed-forward inhibition appears to enhance synaptic plasticity in the FXS amygdala. These results demonstrate that plasticity is enhanced in the amygdala of the juvenile Fmr1 knockout (KO) mouse and that E/I imbalance may underpin anxiety disorders commonly seen in FXS and ASDs.
\end{abstract}

Key words: E/I balance; feed-forward inhibition; fragile X syndrome; lateral amygdala; synaptic plasticity

\section{Significance Statement}

These studies identify significant cellular and synaptic defects in a behaviorally-relevant brain to the pathology of fragile X syndrome (FXS). We find that principal neurons (PNs) in the FXS basolateral amygdala (BLA) exhibit marked hyperexcitability as early as P21. Further, we show that feed-forward inhibition is reduced in the Fmr1 knock-out (KO) LA. This contributes to enhanced synaptic plasticity in LA of the Fmr1KO mouse.

\section{Introduction}

Fragile $X$ syndrome (FXS) is the most common monogenic form of intellectual disability. FXS is a neurodevelopmental disorder (NDD) broadly characterized by neurologic and psychiatric disorders such as attention deficit hyperactivity disorder, anxiety, social avoidance, increased incidence of seizures and epilepsy, and autism

Received March 18, 2021; accepted April 9, 2021; First published April 23, 2021.

The authors declare no competing financial interests. spectrum disorders (ASDs; Hagerman et al., 2009). In humans, FXS is caused by a repeat expansion mutation in the FMR1 gene that encodes fragile $\mathrm{X}$ mental retardation protein (FMRP; Liu et al., 2018). Trinucleotide repeat expansion results in hypermethylation at the FMR1 locus and subsequent transcriptional silencing of FMRP (Fu et

Author contributions: M.N.S., D.R., and M.M.H. designed research; M.N.S., E.M.G., C.A.C.-D.R., and J.K.K. performed research; S.M.B. contributed unpublished reagents/analytic tools; M.N.S., E.M.G., C.A.C.-D.R., J.K.K., S.M. B., and D.R. analyzed data; M.N.S., E.M.G., D.R., and M.M.H. wrote the paper. 
al., 1991). FMRP is an RNA binding protein with a known role in regulating messenger RNA translation during synaptic development (Chen et al., 2003; Darnell et al., 2011). The dysregulation of protein synthesis observed in the pathogenesis of FXS is known to result in significant defects in neuronal development, synaptic and circuit function (Contractor et al., 2015).

In FXS, profound alterations in excitatory and inhibitory neurotransmission have been found across multiple brain regions including the hippocampus, somatosensory cortex, and the basolateral amygdala (BLA; Huber et al., 2002; Olmos-Serrano et al., 2010; Paluszkiewicz et al., 2011; Contractor et al., 2015). Indeed, accumulating evidence directly implicates BLA dysfunction as a key component of many behavioral manifestations in FXS as well as NDDs (Baron-Cohen et al., 2000; Hessl et al., 2004; Bauman and Kemper, 2005; Dalton et al., 2005). Amygdala-based behaviors, including anxiety disorders and social withdrawal, are commonly diagnosed psychiatric disorders in individuals with FXS and ASDs (Tsiouris and Brown, 2004; Turk et al., 2005; Cordeiro et al., 2011). In NDDs such as FXS, patients have increased anxiety and an increased retention of fearful memories (Turk et al., 2005). The adherence to fearful memories dictates the emotional state of the patient (Turk et al., 2005) and likely exacerbates already increased anxiety levels (Meredith et al., 2012). Further, patients with intellectual disabilities can exhibit stress and anxiety from an overactive response to fearful memories, similar to posttraumatic stress and panic disorders (Turk et al., 2005; Roberts et al., 2009).

The amygdala is a grouping of many distinct, heterogeneous nuclei responsible for the integration and processing of information with emotional and social salience (Duvarci and Pare, 2014; Janak and Tye, 2015; Li et al., 2017). Specifically, a large body of work has identified the $B L A$ as the main site of synaptic plasticity underlying the acquisition, expression, and extinction of sensory-threat associations with the BLA also implicated in neuropsychiatric diseases such as anxiety disorders (Duvarci and Pare, 2014; Janak and Tye, 2015). At the cellular level, the BLA is composed of excitatory principal neurons (PNs) and a diverse population of GABAergic inhibitory interneurons (INs; McDonald, 1984; Sah et al., 2003; Duvarci

This work was supported by the National Institutes of Health (NIH) National Research Service Award Individual Predoctoral Fellowship F31 MH124277 (to M.N.S), NIH Grants R01 DC000566 (to D.R.) and R01 NS095311 (to M.M.H), the National Science Foundation Graduate Research Fellowship DGE1553798 (to E.M.G.), and the Fondo Nacional de Desarrollo Científico y Tecnológico Grant 11150816 (to C.A.C.-D.R.)

${ }^{*}$ M.N.S. and E.M.G. contributed equally to this work.

\#D.R. and M.M.H. contributed equally to this work as senior authors.

E. M. Guthman's present address: Princeton Neuroscience Institute, Princeton University, Princeton, NJ 08544.

Correspondence should be addressed to Molly M. Huntsman at molly. huntsman@CUAnschutz.edu

https://doi.org/10.1523/ENEURO.0113-21.2021 Copyright $@ 2021$ Svalina et al.

This is an open-access article distributed under the terms of the Creative Commons Attribution 4.0 International license, which permits unrestricted use, distribution and reproduction in any medium provided that the original work is properly attributed. and Pare, 2014). These local PNs undergo input-specific, activity-dependent plastic changes in response to co-occurring threatening and sensory stimuli (Quirk et al., 1995; McKernan and Shinnick-Gallagher, 1997; Schoenbaum et al., 1999; Nabavi et al., 2014; Grewe et al., 2017; Kim and Cho, 2017; Kasugai et al., 2019). Importantly, these cooccurring stimuli depolarize and drive ensembles of BLA PNs to fire action potentials (APs), and this excitation is necessary for learning to occur (Rosenkranz and Grace, 2002; Wolff et al., 2014; Grewe et al., 2017). The local circuit INs play an important role regulating the synaptic plasticity underlying this in vivo learning process (Bissière et al., 2003; Wolff et al., 2014). Our group and others have shown this inhibitory control is exerted via a feedforward circuit motif from somatostatin-expressing (Sst) INs which modulates long-term potentiation (LTP) at cortical and thalamic afferent synapses onto BLA PNs (Smith et al., 2000; Bissière et al., 2003; Tully et al., 2007; Unal et al., 2014; Wolff et al., 2014; Bazelot et al., 2015; Ito et al., 2019; Guthman et al., 2020). Thus, feedforward inhibition (FFI)-gated LTP is an underlying circuit mechanism for the acquisition of threat conditioning.

In FXS, profound alterations in the GABAergic system have been previously identified in cortex, hippocampus, brainstem, and BLA (El Idrissi et al., 2005; D'Hulst et al., 2006; Gibson et al., 2008; Olmos-Serrano et al., 2010; Paluszkiewicz et al., 2011; Vislay et al., 2013; Martin et al., 2014). Specifically, prior work from our group has shown reductions in both tonic and phasic inhibitory neurotransmission as well as GABA availability have been observed in the rodent BLA (Olmos-Serrano et al., 2010; Martin et al., 2014), the BLA subnucleus where these fundamental plasticity processes first occur in the canonical BLA circuit (Duvarci and Pare, 2014; Janak and Tye, 2015). However, despite the prevalence of amygdala-based disorders in FXS, the synaptic underpinnings remain unclear as there is limited understanding of the role of diminished inhibition in mediating plasticity in this well-defined circuit responsible for sensory-threat processing. Thus, a better understanding of how heightened anxiety may stem from maladaptive plasticity is essential to identifying new therapeutic avenues.

In the present study, we used whole-cell patch clamp electrophysiology to explore the intrinsic properties of LA PNs, local microcircuit excitation-inhibition (E/I) balance, and synaptic plasticity. We found that excitatory PNs in the Fmr1 knock-out (KO) LA show marked hyperexcitability compared with wild-type (WT) animals. Consistent with the role of FFI in gating LTP in the LA, we show a correlated loss of FFI and enhanced LTP in the Fmr1KO LA. These results demonstrate that altered $E / /$ balance in Fmr1KO mice enhances synaptic plasticity in the LA and may underpin behavioral disorders seen in both children with FXS and ASDs.

\section{Materials and Methods}

\section{Ethical approval}

All experiments and procedures were conducted in accordance with protocols approved and reviewed by the 
Institutional Animal Care and Use Committee (\#00039, valid through 3/21/2022) at the University of Colorado Anschutz Medical Campus, in accordance with guidelines from the National Institutes of Health.

\section{Experimental model and subject details}

Slice electrophysiology experiments were conducted on mice aged postnatal day (P)21-P35. Experiments were conducted on both male $\left(F m r 1^{-1 / y}\right)$ and female $\left(F m r 1_{-} /-\right)$ mice. The following mouse lines were used in the experiments: C57BI/6J (The Jackson Laboratory \#000664) and FVB.NH (The Jackson Laboratory \#001800) and B6.129P2$\mathrm{Fmr}^{\mathrm{tm} 1 \mathrm{Cgr}} / \mathrm{J}$ (The Jackson Laboratory \#003025), and FVB.129P2-Pde6 $\mathrm{b}^{+} \mathrm{Tyr}^{\mathrm{c}-\mathrm{ch}} \mathrm{Fmr}^{\mathrm{tm} 1 \mathrm{Cgr}} / \mathrm{J}$ (The Jackson Laboratory \#004624). All mice were obtained from The Jackson Laboratory and housed in polypropylene cages with wood shavings with a modified 10/14 h light/dark cycle. Food and water were available ad libitum.

\section{Acute slice preparation for electrophysiology}

Mice aged P21-P35 were killed by exposure to a rising concentration of carbon dioxide $\left(\mathrm{CO}_{2}\right)$ at $0.5-1.0$ pound per square inch at a $0.5-1 / \mathrm{min}$ flow rate until loss of consciousness followed by decapitation. Brains were quickly removed by dissection and glued cerebellar side-down on a vibratome (Leica Biosystems) stage and immersed in an ice-cold and oxygenated cutting solution $\left(95 \% \mathrm{O}_{2} / 5 \%\right.$ $\mathrm{CO}_{2}$; $45 \mathrm{~mm}$ sucrose, $25 \mathrm{~mm}$ glucose, $85 \mathrm{~mm} \mathrm{NaCl}, 2.5 \mathrm{~mm}$ $\mathrm{KCl}, 1.25 \mathrm{~mm} \mathrm{NaH}_{2} \mathrm{PO}_{4}, 25 \mathrm{~mm} \mathrm{NaHCO} 3,0.5 \mathrm{~mm} \mathrm{CaCl}$, and $7 \mathrm{mM} \mathrm{MgCl}_{2}$, osmolality, 290-300 mOsm/kg). We prepared acute coronal slices $(300 \mu \mathrm{m})$ containing BLA and incubated the slices in oxygenated $\left(95 \% \mathrm{O}_{2} / 5 \% \mathrm{CO}_{2}\right)$ artificial CSF (ACSF; $10 \mathrm{~mm}$ glucose, $124 \mathrm{~mm} \mathrm{NaCl}, 2.5 \mathrm{~mm}$ $\mathrm{KCl}, 1.25 \mathrm{~mm} \mathrm{NaH}_{2} \mathrm{PO}_{4}, 25 \mathrm{~mm} \mathrm{NaHCO}_{3}, 2 \mathrm{~mm} \mathrm{CaCl}_{2}$, and $2 \mathrm{~mm} \mathrm{MgCl}$, osmolality $290-300 \mathrm{mOsm} / \mathrm{kg}$ ) at $36^{\circ} \mathrm{C}$ for at least $30 \mathrm{~min}$. All reagents were purchased from SigmaAldrich.

\section{Electrophysiology}

Slices were placed in a submerged slice chamber and perfused with ACSF heated to $32-34^{\circ} \mathrm{C}$ at a rate of $2 \mathrm{ml} /$ min. Slices were visualized using a moving stage microscope (Scientifica; Olympus) equipped with $4 \times(0.10 \mathrm{NA})$ and $40 \times(0.80 \mathrm{NA})$ objectives, differential interference contrast (DIC) optics, infrared illumination, LED illumination (CoolLED), a CoolSNAP EZ camera (Photometrics), and Micro-Manager 1.4 (Open Imaging). Whole cell patch clamp recordings were made using borosilicate glass pipettes (2.5-5.0 MW; King Precision Glass) filled with an intracellular recording solution. Data were acquired with a Multiclamp 700B amplifier and were converted to a digital signal with the Digidata 1440 digitizer using PCLAMP 10.6 software (Molecular Devices).

Recordings were obtained from visually identified excitatory PNs in the LA. PNs were targeted based on their large, pyramidal-like soma and strict biophysical criteria based on Sah et al., 2003) and our previous studies (Olmos-Serrano et al., 2010; Vislay et al., 2013; Martin et al., 2014). For voltage clamp experiments, a cesium methanesulfonate (CsMe) based intracellular solution was used (120 mм CsMe, 10 mm HEPES, 0.5 mm EGTA, 8 mm $\mathrm{NaCl}, 10 \mathrm{~mm}$ Na-phosphocreatine, $1 \mathrm{~mm}$ QX-314, $4 \mathrm{~mm}$ MgATP, and $0.4 \mathrm{~mm} \mathrm{Na}_{2} \mathrm{GTP}, \mathrm{pH}$ to 7.3 with $\mathrm{CsOH}$; osmolality adjusted to $\sim 290 \mathrm{mOsm} / \mathrm{kg}$ ). For all current clamp and plasticity experiments, a potassium gluconate based intracellular solution was used $(135 \mathrm{~mm}$ potassium gluconate, $10 \mathrm{~mm}$ HEPES, $20 \mathrm{~mm} \mathrm{KCl,} 0.1 \mathrm{~mm}$ EGTA, 2 mм MgATP, and $0.3 \mathrm{~mm} \mathrm{Na}_{2} \mathrm{GTP}$, pH to 7.3 with $\mathrm{KOH}$; osmolality adjusted to $\sim 295 \mathrm{mOsm} / \mathrm{kg}$ ). Access resistance was monitored throughout the experiments and data were discarded if access resistance exceeded $25 \mathrm{M} \Omega$ or varied by $>20 \%$. No junction potential compensation was performed. Series resistance was not compensated in either voltage or current clamp. In current clamp, compensation for voltage variations was achieved using a bridge balance circuit. In voltage clamp, during recording of small synaptic (spontaneous and evoked) events, series resistance was monitored throughout the experiment. Data were sampled at $10 \mathrm{kHz}$ and lowpass filtered at $4 \mathrm{kHz}$. Offline, current data were filtered using either a third order Savistky-Golay filter with a $\pm 0.5-\mathrm{ms}$ window or a $2-\mathrm{kHz}$ lowpass butterworth filter. Mean traces were created by first aligning all events by their point of maximal rise (postsynaptic currents) and then obtaining the mean of all events.

\section{Electrophysiology experimental design}

Ramped current injections. Immediately after achieving whole-cell configuration, LA neurons were recorded at rest in current clamp mode $\left(I_{\text {hold }}=0 \mathrm{pA}\right)$. Following a three second baseline period, the holding current was linearly ramped from 0 to $400 \mathrm{pA}$ over $2 \mathrm{~s}$. A total of 25 sweeps of data were collected for each neuron, and the data were used to determine the resting membrane potential $\left(V_{\text {rest }}\right)$, AP threshold, and rheobase current of LA PNs.

Square current injections. Following ramped current injections, we recorded the responses of LA neurons to a series of square hyperpolarizing and depolarizing current injections. Before initiation of the series of current injections, $V_{m}$ of the LA neurons was adjusted to approximately $-60 \mathrm{mV}$. Each cell was subjected to two series of 600-ms square current injections: -100 to $+100 \mathrm{pA}$ at $10-p A$ intervals and -200 to +400 pA at $25-p A$ intervals. The data collected in these experiments were used to determine active and passive membrane properties of the neurons.

Spontaneous (s)EPSCs/sIPSCs. sEPSCs $\left(N_{\text {hold }}=-70 \mathrm{mV}\right)$ and sIPSCs $\left(N_{\text {hold }}=0 \mathrm{mV}\right)$ in LA PNs were recorded for $80 \mathrm{~s}$ each.

Input-output curves. Thalamic afferents from the internal capsule were stimulated using a bipolar stimulating electrode (FHC). We recorded evoked EPSCs ( $\mathrm{V}_{\text {hold }}=$ $-70 \mathrm{mV})$ and IPSCs $\left(V_{\text {hold }}=0 \mathrm{mV}\right)$ from LA PNs in response to internal capsule stimulation. Experiments were conducted over a range of stimulation intensities (0-100 $\mu \mathrm{A}$ with a $10-\mu \mathrm{A}$ interval).

Paired-pulse EPSC experiments. Thalamic afferents from the internal capsule were stimulated twice at 10 and $50 \mathrm{~Hz}$ (100- and 20-ms interstimulus intervals) at a 100- $\mu \mathrm{A}$ 
stimulus intensity. Evoked EPSCs $\left(V_{\text {hold }}=-70 \mathrm{mV}\right)$ from LA PNs in response to this stimulation.

Synaptic plasticity. For LTP experiments, we recorded AMPA mediated-EPSCs elicited by electrical stimulation of the internal capsule (stimulation frequency $=0.066 \mathrm{~Hz}$ ) in LA PNs from WT and Fmr1KO mice at P21-P35 (voltage-clamp configuration, $V_{\text {hold }}=-80 \mathrm{mV}$ ) in the presence or absence of the GABA $A_{A}$ receptor antagonist, gabazine (SR-95531, $10 \mu \mathrm{m}$ in DMSO, Tocris Biosciences). Following a 5-min baseline recording, high-frequency electrical stimulation (HFS; two trains of 100 pulses delivered at $100 \mathrm{~Hz}, 20 \mathrm{~s}$ apart) were delivered to the internal capsule. EPSCs were measured for 20-45 min after HFS in the same way as baseline recordings. Synaptic strength was quantified as the integrated charge of each evoked EPSC. Change in synaptic strength was determined by normalizing the integrated charge of each EPSC recorded both before and after HFS to the average integrated charge of all baseline recordings (average normalized integrated charge of baseline $=100 \%$ ). Successful LTP induction was defined as a significant increase in normalized integrated charge during the last $5 \mathrm{~min}$ (minutes 16-20) after HFS compared with baseline (minutes -5 to -1$)$.

\section{Definitions of electrophysiological parameters}

$V_{\text {rest }} \cdot V_{\text {rest }}$ was defined as the mean $V_{m}\left(I_{\text {hold }}=0 \mathrm{pA}\right)$ during a 500-ms baseline across all sweeps in the ramped injection experiments.

AP threshold. AP threshold was defined as the voltage at which $\mathrm{dV} / \mathrm{dt}$ exceeded $20 \mathrm{~V} / \mathrm{s}$. AP threshold was calculated at the first AP of each sweep in the ramped injection experiments.

Rheobase current. Rheobase current was defined as the mean current injected at AP threshold for the first AP across all sweeps in the ramped injection experiments.

Membrane resistance $\left(R_{m}\right)$. $R_{m}$ was defined as the slope of the best fit line of the I-V plot using the -100 to +100 pA (10-pA steps) series of current injections. Mean voltage response to each current injection step was defined as the difference between baseline mean membrane voltage (100 ms before current injection) and the mean membrane voltage during the $100-\mathrm{ms}$ period from $50 \mathrm{~ms}$ after the start of the injection to $150 \mathrm{~ms}$ after the start of the current injection. This 100-ms window was chosen to allow for measurement of the change in $V_{m}$ after the membrane had charged and before any potential $\mathrm{HCN}$ channel activation. The I-V plot was constructed using all current steps below rheobase.

Maximum firing rate. Maximum firing rate was defined as the inverse of the interspike interval (ISI) during the first 200 ms of the most depolarizing current injection step before attenuation of AP firing was observed. Maximum firing rate was calculated using the -200 to $+400 \mathrm{pA}$ (25pA steps) series of current injections.

AP amplitude. Amplitude of the AP was defined as the voltage difference between the peak of the AP and its threshold potential (set at $\mathrm{dV} / \mathrm{dt}=20 \mathrm{~V} / \mathrm{s}$ ). AP amplitude was calculated at the rheobase sweep of the -200 to $+400 \mathrm{pA}$ (25-pA steps) series of current injections.
AP halfwidth. AP halfwidth was defined as the time between the half-amplitude point on the upslope of the AP waveform to the half-amplitude point on the downslope of the AP waveform. AP halfwidth was calculated at the rheobase sweep of the 200 to +400 pA (25-pA steps) series of current injections.

After-hyperpolarization potential (AHP) magnitude. AHP magnitude was defined as the difference between the most hyperpolarized membrane voltage of the AHP (occurring within $100 \mathrm{~ms}$ after AP threshold) and AP threshold. AHP magnitude and latency data were calculated at the rheobase sweep of the -200 to +400 pA (25$\mathrm{pA}$ steps) series of current injections. $\triangle \mathrm{AHP}$ data were calculated at the rheobase $+50-\mathrm{pA}$ sweep of the -200 to $+400 \mathrm{pA}$ (25-pA steps) series of current injections.

AHP latency. AHP latency was defined as the time from AP threshold and the peak of the AHP.

$\triangle A H P$. $\triangle \mathrm{AHP}$ was defined as the difference between the first and last $\mathrm{AHP}\left(\triangle \mathrm{AHP}=\mathrm{AHP}_{\text {last }}-\mathrm{AHP}_{\text {first }}\right)$.

$A P$ phase plot. The AP phase plot was obtained by plotting the rate of change of the mean AP for each cell from the rheobase sweep of the -200 to +400 pA (25-pA steps) series of current injections as a function of the corresponding membrane voltage.

Latency to first AP. AP latency was defined as the time from the initiation of the current injection to the peak of the first AP. AP latency was calculated at the rheobase sweep of the -200 to $+400 \mathrm{pA}(25-\mathrm{pA}$ steps) series of current injections.

Firing rate adaptation ratio. Firing rate adaptation was defined as the ratio of the first and the average of the last two ISIs, such that firing rate adaptation $=\mid I_{\text {first }} /$ meanISI last two ISI. Firing rate adaptation was calculated at the rheobase +50-pA sweep of the -200 to +400 pA (25pA steps) series of current injections.

$A P$ broadening. AP broadening was defined as the ratio of the AP halfwidths of the first two APs (broadening $=$ halfwidth second $_{\text {halfwidth }}$ (irst). AP broadening was calculated at the rheobase +50-pA sweep of the -200 to $+400 \mathrm{pA}$ (25-pA steps) series of current injections.

AP amplitude adaptation. AP amplitude adaptation was defined as the ratio of the AP amplitude of the average of the last three APs and the first AP, such that AP amplitude adaptation $=$ meanamplitude last $3 \mathrm{APs} / \mathrm{amplitu}$ -

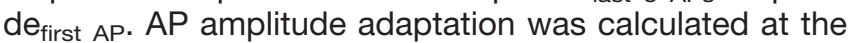
rheobase $+50-\mathrm{pA}$ sweep of the -200 to $+400 \mathrm{pA}$ (25-pA steps) series of current injections.

Membrane decay $\tau$. Membrane decay $\tau$ was determined by using a single exponential fit, $f(t)=A e^{-t / \tau}$ to fit the change in $V_{m}$ induced by a $-100-p A$ sweep in the -100 to $+100 \mathrm{pA}$ (25-pA steps) series of current injections.

Hyperpolarization-induced sag. Hyperpolarization-induced sag was calculated using the equation, $V \min -V s s$

$\frac{V m i n-V s s}{V \min -V b l} \times 100 \%$, where $V_{\min }$ was defined as the most hyperpolarized membrane voltage during the current injection, $\mathrm{V}_{\mathrm{ss}}$ was defined as the mean steadystate membrane voltage (last $200 \mathrm{~ms}$ of the current 
injection), and $V_{b l}$ was defined as the mean baseline membrane voltage (100 ms before current injection). Hyperpolarization-induced sag was measured from the $-200-p A$ current injection.

Rebound spikes. Rebound spikes were defined as the number of APs in the $500 \mathrm{~ms}$ following the -200-pA current injection.

sEPSC/IPSC detection and amplitude. sEPSC/IPSCs were detected by a combined template and threshold method. Briefly, a template was made by subsampling $10 \%$ of local peaks exceeding at least $6 \times$ or $7 \times$ (sEPSC or sIPSC, respectively) the median absolute deviation of a rolling baseline current (50 ms before the peak). The template current was then truncated from its $20 \%$ rise point through the end of the decay time constant for the template current. Next, all local peaks exceeding $6 \times$ or $7 \times$ the median absolute deviation of a rolling baseline current ( $50 \mathrm{~ms}$ before the peak) were collected. The template was then scaled to each individual putative SEPSC or SIPSC peak and each peak was assigned a normalized charge integral relative to the template. Finally, a normalized charge integral cutoff was chosen to exclude obvious noise/non-physiological events below a certain normalized charge integral. sEPSC amplitude was defined as the difference between the peak amplitude of each detected current and its corresponding baseline current. sEPSC/ IPSC amplitude for each cell was defined as the median peak amplitude for that cell. sEPSC/IPSC frequency was defined as the inverse of the interevent intervals of the events. The frequency measure for each neuron was defined as the median of the SEPSC/IPSC frequencies for that cell.

sEPSC/IPSC $20-80 \%$ risetime. A total of $20-80 \%$ risetime was defined as the time it took an SEPSC or SIPSC to reach $80 \%$ of its peak amplitude from $20 \%$ of its peak amplitude; $20-80 \%$ risetime was calculated from the mean sEPSC/sIPSC of a given LA PN.

EPSC/IPSC $\tau_{\text {Decay. }}$ EPSC $\tau_{\text {Decay }}$ was determined using a single exponential fit, $\mathrm{f}(\mathrm{t})=\mathrm{A} e^{-t / \tau}$. IPSC $\tau_{\text {Decay }}$ was defined as the weighted time-constant of IPSC decay. Briefly, a double exponential fit, $f(t)=\mathrm{A}_{1} e^{-t / \tau 1}+\mathrm{A}_{2} e^{-t / \tau 2}$, was used to obtain the parameters to determine the weighted time-constant where $\tau_{\text {Weighted }}=\left(\tau_{1} \mathrm{~A}_{1}+\tau_{2} \mathrm{~A}_{2}\right) /$ $\left(A_{1}+A_{2}\right)$. For spontaneous events, the mean cellular EPSC or IPSC was used to determine the decay kinetics. For evoked events, the mean cellular EPSC or IPSC in response to $100-\mu \mathrm{A}$ stimulation was used to determine the decay kinetics.

EPSC/IPSC detection and amplitude, input-output curves. To determine the evoked EPSC and IPSC amplitudes across varying stimulus intensities, we first determined the peak time relative to the $100-\mu \mathrm{A}$ stimulation. Then, we defined EPSC or IPSC amplitude as the maximum positive or negative deflection, respectively, from the mean current response within a window of 6 SDs of the peak time jitter.

Stimulation for half-maximum EPSC/IPSC amplitude. To get the half-maximum stimulation intensity and the slope of the input-output curve, we used the least squares method to fit a line to the EPSC/IPSC output relative to stimulation input. We only used input values that elicited non-zero EPSC/IPSC amplitudes to determine the best fit line. We then used this best fit line to find the stimulation intensity that was associated with $50 \%$ of the maximum EPSC/IPSC amplitude for the PN.

Input-output curve slope. We defined input-output slope as the slope of the line created with a least squares fit of the input-output curve.

Paired-pulse ratio. To determine paired pulse ratio, we first determined the peak amplitude of the maximum negative deflection from the mean current trace during the poststimulus period (20 or $100 \mathrm{~ms}$ poststimulation) for each of the paired stimulations. We defined the pairedpulse ratio such that paired-pulse ratio $=$ amplitude $_{\mathrm{EPSC}}$, second/amplitude EPSC,first.

\section{Statistics}

Statistical analyses

All data analysis was performed using custom written MATLAB code and GraphPad Prism. Normality of the data were assessed using the Anderson-Darling test. For a test between two groups normal data, an unpaired $t$ test was used. For tests between two groups of non-normal data, a Mann-Whitney $U$ (MWU) test was used. For examination of paired pulse experiment results across genotype, a two-way repeated measures ANOVA was used. Genotype was used as the between-subjects model and interstimulus interval was used as the within-subjects model. All statistical tests were two-tailed. Unless otherwise stated, experimental numbers are reported as $n=x$, $y$, where $\mathrm{x}$ is the number of neurons and $\mathrm{y}$ is the number of mice.

\section{Data display}

Data visualizations were created in MATLAB, GraphPad Prism and Adobe Illustrator. Normal data are presented as the mean \pm SD. Non-normal data are presented as the median with error bars extending along the interquartile range.

\section{Data and software availability statement}

Data and code are available on request, and code will be made available on GitHub at https://github.com/ emguthman.

\section{Reagent and resource sharing}

Further information and requests for resources and reagents should be directed to and will be fulfilled by corresponding author.

\section{Results}

\section{LA PNs in Fmr1KO mice exhibit marked hyperexcitability}

To examine potential differences in neuronal excitability, we prepared acute coronal brain slices containing the BLA. We performed whole cell patch-clamp recordings of LA PNs and compared their intrinsic biophysical properties across WT and Fmr1KO juvenile mice (P21-P35). In these experiments, we measured 18 
A
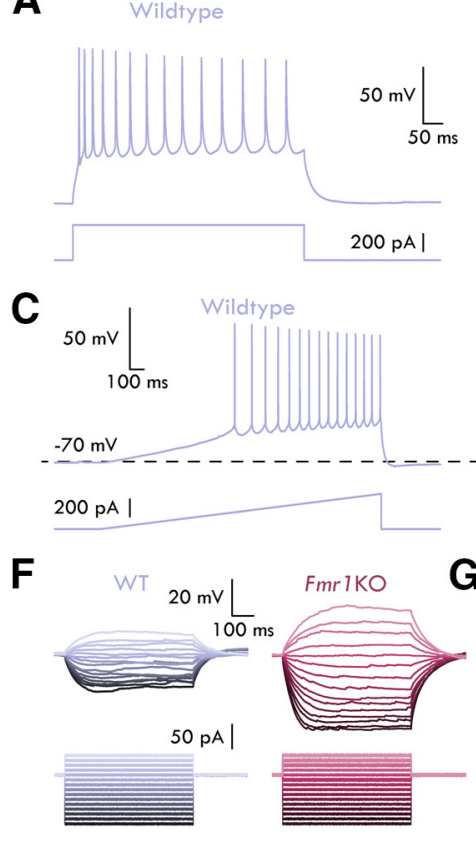

c
B
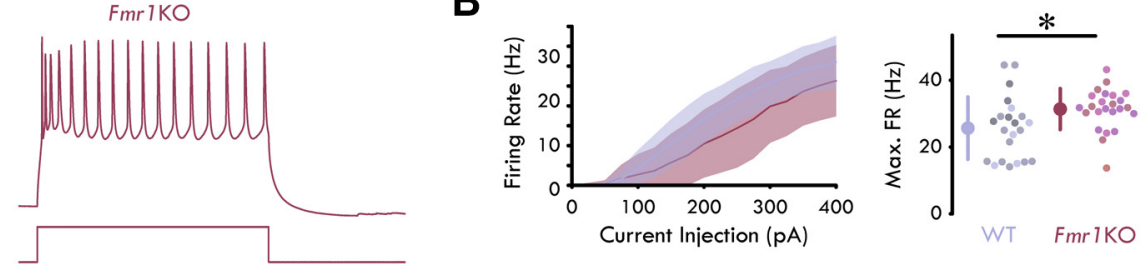

D

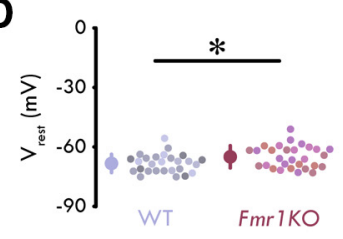

E

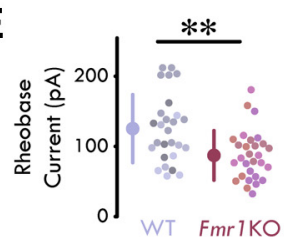

Figure 1. Hyperexcitability of PNs in Fmr1KO LA. $\boldsymbol{A}$, Representative traces of maximum firing rate response to rectangular current injections in WT and Fmr1KO LA PNs. B, left, Mean firing rate of LA PNs. Shading shows SD. Right, Maximum firing rate of LA PNs is greater in Fmr1KO compared with WT LA [unpaired $t$ test: $p=0.0175 ; n_{\mathrm{WT}}=22$ neurons, 3 mice, 2 males (M), 1 female (F); $n_{\text {Fmr1KO }}=24,4,3 \mathrm{M}, 1 \mathrm{~F}$. C, Representative traces of voltage response to a ramped current injection in WT and Fmr1KO LA PNs. $D$, Fmr1KO LA PNs have a more depolarized $\mathrm{V}_{\text {rest }}$ compared with WT LA PNs (unpaired $t$ test: $p=0.0189 ; n_{\mathrm{WT}}=27,4,3 \mathrm{M}, 1 \mathrm{~F}$; $n_{\text {Fmr1KO }}=29,4,3 \mathrm{M}, 1 \mathrm{~F}$ ). E, Fmr1KO LA PNs have a lower rheobase current from rest compared with WT LA PNs (unpaired $t$ test: $\left.p=0.00135 ; n_{\mathrm{WT}}=27,4,3 \mathrm{M}, 1 \mathrm{~F} ; n_{\mathrm{Fmr} 1 \mathrm{KO}}=29,4,3 \mathrm{M}, 1 \mathrm{~F}\right)$. $\boldsymbol{F}$, Representative traces of voltage responses to intermediate current injection traces used to determine $\mathrm{R}_{\mathrm{m}}$ and decay $\tau(-100$ to $+100 \mathrm{pA} ; \Delta 10 \mathrm{pA}) . \mathbf{G}, \mathrm{R}_{\mathrm{m}}$ is increased in Fmr1KO LA PNs compared with WT LA PNs (MWU test: $p=0.0016 ; n_{\mathrm{WT}}=22,3,2 \mathrm{M}, 1 \mathrm{~F} ; n_{\text {Fmr1Ko }}=24,4,3 \mathrm{M}, 1 \mathrm{~F}$ ). $\boldsymbol{H}$, Membrane decay $\tau$ is increased in Fmr1KO LA PNs compared with WT LA PNs (MWU test: $p=0.00160 ; n_{\mathrm{WT}}=22,3,2 \mathrm{M}, 1 \mathrm{~F} ; n_{F m r 1 \mathrm{Ko}}=24,4,3 \mathrm{M}, 1 \mathrm{~F}$ ). $\boldsymbol{I}$, Left, Representative AP traces from a WT and Fmr1KO LA PN at rheobase current injection. Right, Phase plot for the same APs. $J$, Fmr1KO LA PNs have broader AP halfwidths compared with WT LA PNs (MWU test: $p=0.00336 ; n_{\mathrm{WT}}=22,3,2 \mathrm{M}, 1 \mathrm{~F} ; n_{\text {Fmr1KO }}=$ $24,4,3 \mathrm{M}, 1 \mathrm{~F})$. Summary statistics in $\boldsymbol{B}, \boldsymbol{D}, \boldsymbol{E}$ presented as mean $\pm \mathrm{SD}$. Summary statistics in $\boldsymbol{H}, \boldsymbol{J}$ presented as median with IQR; ${ }^{*} p<0.05,{ }^{* *} p<0.01$. Individual neurons plotted and represented by different colors on a per animal basis.

membrane properties (Fig. 1; Table 1) by examining voltage responses to both a ramped and rectangle current injections (see Materials and Methods).

We observed significant differences in both active and passive membrane properties of LA PNs in Fmr1KO compared with WT animals. Specifically, depolarizing current injections drove increased AP firing rates in LA PNs of Fmr1KO compared with WT animals [unpaired $t$ test: $p=0.0175$, mean difference (MD): $5.71 \mathrm{~Hz}$, confidence interval (Cl): $[-10.4,-1.05] ; n_{\mathrm{WT}}=22$ neurons, three mice; $n_{\text {Fmr1KO }}=24$, 4; Fig. $\left.1 A, B\right]$. Additionally, PNs in the LA of Fmr1KO mice exhibited a higher $\mathrm{V}_{\text {rest }}$ and a lower rheobase current compared with PNs in WT mice $\left(\mathrm{V}_{\text {rest }}\right.$, unpaired $t$ test: $p=0.0189$, MD: $-3.34 \mathrm{mV}, \mathrm{Cl}:[-6.10$, -0.57 ]; rheobase current: unpaired $t$ test: $p=0.00135$, MD: $38.12 \mathrm{pA}, \mathrm{Cl}:[15.5,60.7], n_{\mathrm{WT}}=22,3 ; n_{\text {Fmr } 1 \mathrm{KO}}=24$, 4; Fig. 1C-E). Further, LA PNs in Fmr1KO mice showed increased $\mathrm{R}_{\mathrm{m}}$, increased membrane decay $\tau$, and AP halfwidth $\left(\mathrm{R}_{\mathrm{m}}, \mathrm{MWU}\right.$ test: $p=0.00160, \mathrm{MD}: 5.68 \mathrm{~ms}, \mathrm{z}:-2.41$, rank-sum: 407; decay $\tau$, MWU test: $p=0.0016$; halfwidth, MWU test: $p=0.00336$, MD: $0.28 \mathrm{~ms}, \mathrm{z}:-2.93$, rank-sum: $384 ; n_{\mathrm{WT}}=22,3 ; n_{\text {Fmr } 1 \mathrm{KO}}=24$, 4; Fig. $\left.1 F-J\right)$. No other membrane property comparisons reached statistical significance (Table 1). Overall, these data reveal increased intrinsic membrane excitability in the LA PNs of Fmr1KO compared with WT mice.

\section{Alterations in spontaneous excitation and inhibition in Fmr1KO LA}

Previous studies from our group identified defects in BLA inhibitory neurotransmission such that the frequency and amplitude of both phasic and tonic IPSCs are reduced during the P21-P35 development time point (Olmos-Serrano et al., 2010; Vislay et al., 2013; Martin et al., 2014). One possible explanation for this reduction could be that it is a homeostatic response to a concomitant change in sEPSCs. However, our previous studies on synaptic transmission were done in the presence of NMDA and AMPA receptor antagonists (D-APV and DNQX, respectively) to induce a complete excitatory blockade and isolate sIPSCs (Olmos-Serrano et al., 2010; Vislay et al., 2013). To study how loss of $F m r 1$ contributes to both spontaneous glutamatergic and GABAergic 
Table 1: Differences in active and passive membrane properties among LA PNs in WT and Fmr1KO mice.

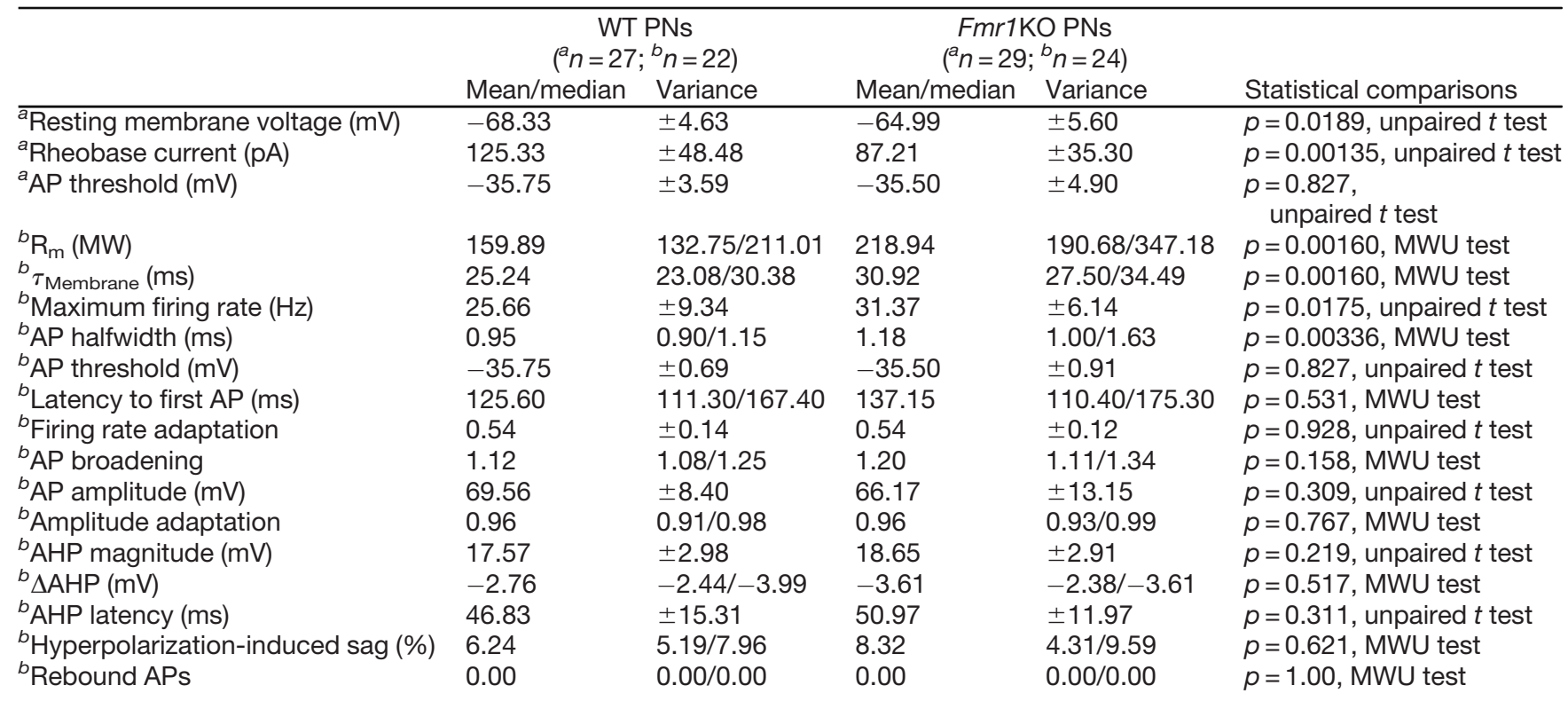

Normal data are presented as mean $\pm \mathrm{SD}$ with differences tested using an unpaired $t$ test. Non-normal data are presented as median and IQR with differences tested using a MWU test.

synaptic transmission in intact LA, we performed patchclamp recordings in local PNs of Fmr $1 \mathrm{KO}$ and WT animals using a CsMe-based intracellular solution. This solution allows us to voltage clamp the PNs at $-70 \mathrm{mV}$ to isolate sEPSCs and $0 \mathrm{mV}$ to isolate sIPSCs (Fig. 2A,F).

We found that sEPSCs from PNs in Fmr1KO LA showed an increase in SEPSC amplitude relative to WT controls (unpaired $t$ test, $p=0.0129 \mathrm{MD}: 1.35 \mathrm{pA}, \mathrm{Cl}$ : [0.425, 3.28], $n_{\mathrm{WT}}=12$ neurons, 7 mice; $n_{\text {Fmr1Ko }}=16$, 5; Fig. $2 B$ ). We found no differences in the frequency or $20 \%-80 \%$ risetime (frequency: unpaired $t$ test, $p=0.166$; risetime: MWU test, $p=0.646 ; n_{\mathrm{WT}}=12,7 ; n_{F m r 1 \mathrm{Ko}}=16$, 5; Fig. $\left.2 C, D\right)$. Additionally, sEPSCs from PNs in Fmr1KO showed a significantly decreased decay $\tau$ (unpaired $t$ test, $p=0.031$, MD: 0.49 ms, Cl: $[0.0570,1.06] ; n_{\mathrm{WT}}=12,7, n_{\text {Fmr1Ko }}=16$, 5; Fig. 2E). When we examined sIPSCs, we found no change in SIPSC amplitude; however, we found an increase in the frequency of sIPSCs onto local PNs (amplitude: unpaired $t$ test, $p=0.127$; frequency: MWU test, $p=0.0161, \mathrm{z}:-2.41$, rank-sum: $174 ; n_{\mathrm{WT}}=15,7 n_{\text {Fmr1 KO }}=$ 15, 4; Fig. 2G,H). As with sEPSCs, we found no significant difference in the $20 \%-80 \%$ risetime of PNs in Fmr1KO and WT LA (MWU test, $p=0.504, n_{\mathrm{WT}}=15,7 ; n_{F m r 1 \mathrm{Ko}}=$ 15, 4; Fig. 2l). However, LA PNs in Fmr1KO mice exhibited a decrease in sIPSC decay (unpaired $t$ test, $p=0.0390$, MD: $1.17 \mathrm{~ms}, \mathrm{Cl}:[0.0842,3.02], n_{\mathrm{WT}}=15,7, n_{\text {Fmr1Ko }}=15$, 4; Fig. 2J). Taken together, these data identify differences in presynaptic and postsynaptic modulation of excitatory and inhibitory neurotransmission in the LA of Fmr1KO mice.

\section{FFI is reduced in Fmr1KO LA}

Disrupted E/I balance of neuronal networks is a hallmark of NDDs (Nelson and Valakh, 2015). In FXS, this manifests as an increased prevalence of anxiety, epilepsy, and attention deficit and hyperactivity (Musumeci et al., 1999; Rogers et al., 2001; Clifford et al., 2007). To further test the hypothesis that loss of Fmr1 leads to a disruption in local circuit E/I balance, we measured the amplitudes of evoked EPSCs and IPSCs in LA PNs following stimulation of the internal capsule. The internal capsule carries thalamic afferents to the LA (LeDoux et al., 1991). We focused on this afferent synapse as it is a major site of the input-specific LTP that underlies the acquisition of classical Pavlovian threat conditioning in vivo (McKernan and Shinnick-Gallagher, 1997; Namburi et al., 2015).

Similar to the spontaneous synaptic event experiments above, we isolated evoked EPSC and IPSCs by voltage clamping LA PNs at -70 and $0 \mathrm{mV}$, respectively. To determine how loss of Fmr1 affects feedforward excitatory and inhibitory drive onto LA PNs, we recorded evoked EPSCs and IPSCs over a stimulus intensity range of $0-100 \mu \mathrm{A}$ (Fig. $3 A, B$ ). We found that loss of Fmr1 had no effect on feedforward excitatory drive to LA PNs as measured by either the stimulation intensity for the half-maximal EPSC amplitude or the slope of the input-output function (halfmax stimulation intensity: unpaired $t$ test, $p=0.0754$; input-output slope: unpaired $t$ test, $p=0.944$; decay $\tau$ : unpaired $t$ test, $p=0.641 ; n_{\mathrm{WT}}=7$ neurons, 5 mice; $n_{F \operatorname{mr} 1 \mathrm{KO}}$ = 6, 3; Fig. $3 A-F$ ). However, we found that feedforward inhibitory drive was reduced in LA PNs of Fmr1KO mice. Specifically, we found that loss of Fmr1 led to an increase in the stimulation intensity for half-maximal IPSC amplitude in LA PNs (unpaired $t$ test, $p=0.0168, M D: 1.48 \mu \mathrm{A}$, Cl: $[-31.1,-3.74] ; n_{\mathrm{WT}}=7,4 ; n_{\text {Fmr1Ko }}=7$, 3; Fig. $3 H$ ). There was no effect of loss of Fmr1 on the slope of the input-output function or evoked IPSC decay (unpaired $t$ test, $p=0.623, n_{\mathrm{WT}}=7,4 ; n_{\text {Fmr1Ko }}=7,3$; decay $\tau$ : 
A

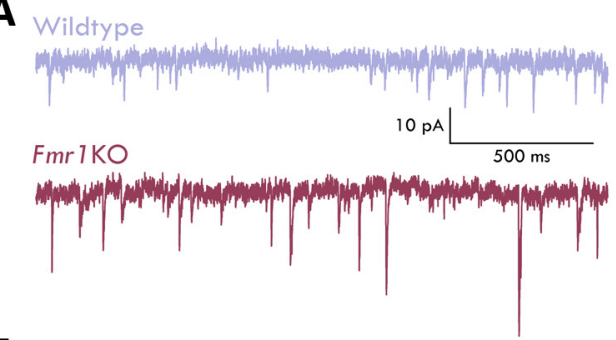

$\mathbf{F}$

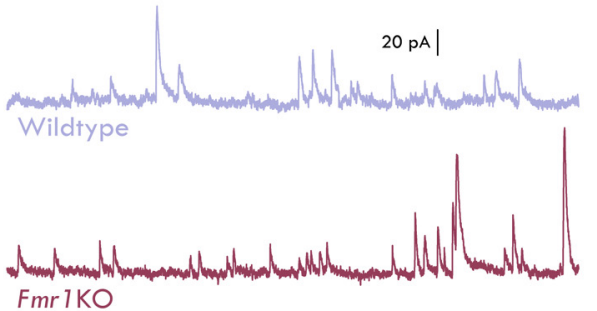

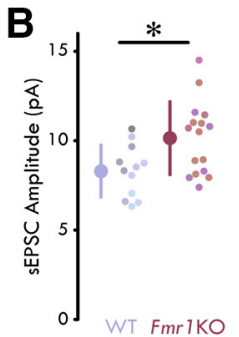
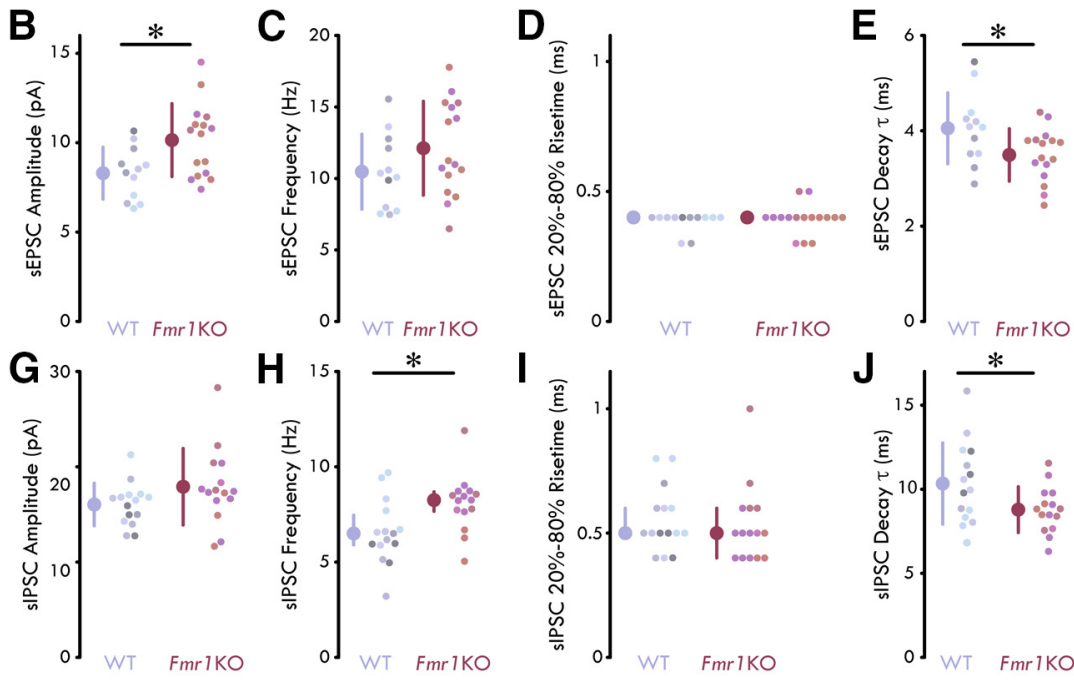

Figure 2. Enhanced sEPSC and sIPSC in Fmr1KO LA. $\boldsymbol{A}$, Representative current traces from LA PNs held at $-70 \mathrm{mV}$. $\boldsymbol{B}$, sEPSC amplitude is increased in LA PNs of Fmr1KO mice [unpaired $t$ test: $p=0.0129 ; n_{\mathrm{WT}}=12$ neurons, 7 mice, 7 males (M); $n_{F m r 1 \mathrm{KO}}=16,5$, $5 \mathrm{M}$. C , No significant difference in sEPSC frequency in LA PNs between WT and Fmr1KO mice (unpaired $t$ test: $p=0.166 ; n_{\mathrm{WT}}=$ 12, 7, $\left.7 \mathrm{M} ; n_{\text {Fmr1KO }}=16,5,5 \mathrm{M}\right)$. $\boldsymbol{D}$, No significant difference in sEPSC risetime in LA PNs between WT and Fmr1KO mice (MWU test: $p=0.646 ; n_{\mathrm{WT}}=12,7,7 \mathrm{M} ; n_{\mathrm{Fmr} 1 \mathrm{KO}}=16,5,5 \mathrm{M}$ ). $\boldsymbol{E}$, sEPSC decay $\tau$ is reduced in LA PNs of Fmr1KO mice (unpaired $t$ test: $\left.p=0.0305 ; n_{\mathrm{WT}}=12,7,7 \mathrm{M} ; n_{F m r 1 \mathrm{KO}}=16,5,5 \mathrm{M}\right)$. F, Representative current traces from LA PNs held at $0 \mathrm{mV}$. G, No significant difference in sIPSC amplitude in LA PNs between WT and Fmr1KO mice (unpaired $t$ test: $p=0.127 ; n_{\mathrm{WT}}=15,7,7 \mathrm{M} ; n_{F m r 1 \mathrm{KO}}=15,4$, $4 \mathrm{M}) . \boldsymbol{H}$, sIPSC frequency is increased in LA PNs of Fmr1KO mice (MWU test: $p=0.0161 ; n_{\mathrm{WT}}=15,7,7 \mathrm{M} ; n_{F m r 1 \mathrm{KO}}=15,4,4 \mathrm{M}$ ). $\boldsymbol{I}$, No significant difference in sIPSC risetime in LA PNs between WT and Fmr1KO mice (MWU test: $p=0.504 ; n_{\mathrm{WT}}=15,7,7 \mathrm{M}$; $n_{\text {Fmr1KO }}=15,4,4 \mathrm{M}$ ). $J$, sIPSC decay $\tau$ is reduced in LA PNs of Fmr1KO mice (unpaired $t$ test: $p=0.0390 ; n_{\mathrm{WT}}=15,7,7 \mathrm{M} ; n_{\text {Fmr1KO }}$ $=15,4,4 \mathrm{M})$. Summary statistics in $\boldsymbol{C}, \boldsymbol{E}, \boldsymbol{G}, \boldsymbol{J}$ presented as mean \pm SD. Summary statistics in $\boldsymbol{D}, \boldsymbol{H}, \boldsymbol{I}$ presented as median with IQR; ${ }^{*} p<0.05$. Individual neurons plotted and represented by different colors on a per animal basis.

unpaired $t$ test, $p=0.142, n_{\mathrm{WT}}=7,5 ; n_{\text {Fmr1KO }}=5$, 3; Fig. $3 /, J)$. These data indicate that a greater amount of activation of the thalamic afferents to LA is needed to drive similar FFI onto PNs in Fmr1KO compared with WT mice. However, the lack of change in input-output slope indicates that once afferent activity is sufficient to elicit IPSCs in the postsynaptic PNs, the IPSC amplitudes increase as a similar function of afferent activity. This finding is in accordance with prior work showing increased feedforward E/I balance in cortical microcircuits Fmr1KO mice at the same developmental time point (Antoine et al., 2019). For example, we also observed a modest decrease in evoked excitation. While not statistically significant, this scaling may be biologically significant as computational modeling suggests that a range of mean predicted changes in overall PSP peak serve to maintain stable E/I balance.

Finally, we compared the presynaptic strength of the thalamic afferents onto LA PNs. To do this, we performed experiments where we stimulated the thalamic afferents in quick succession (20- and 100-ms interstimulus intervals) while recording EPSCs in the postsynaptic LA PN. These experiments revealed a selective increase in the paired-pulse ratio in LA PNs of Fmr1KO mice (two-way repeated measures ANOVA, $p_{\text {Main Effect: }}$ genotype $=0.0465, p_{\text {Main Effect: interstimulus interval }}=$ $1.56 \times 10^{-5}, n_{\mathrm{WT}}=6,4 ; n_{\text {Fmr1KO }}=5$, 3; Fig. $\left.3 K, L\right)$. Taken together, these data indicate a specific disruption of local E/I balance caused by a reduction in FFI onto local PNs in the Fmr1KO LA.

\section{Reduced FFI enhances synaptic plasticity during early development}

Local INs provide FFI onto PNs to gate LTP in BLA microcircuits (Bissière et al., 2003; Tully et al., 2007; Wolff et al., 2014; Bazelot et al., 2015), and LTP cannot be induced in PNs if local inhibition is intact (Bissière et al., 2003). In light of the observed reduction in FFI onto LA PNs in Fmr1KO mice (Fig. 3), we hypothesized that it would be possible to induce LTP in Fmr1KO LA without manipulating GABAergic neurotransmission. To test this hypothesis, we recorded EPSCs in LA PNs following stimulation of the internal capsule in the presence and absence of the $\mathrm{GABA}_{\mathrm{A}}$ receptor blocker gabazine (gbz; 10 $\mu \mathrm{M}$; Fig. 4). After a stable 5-min baseline recording (stimulation frequency $=0.066 \mathrm{~Hz}$ ), a high-frequency tetanus stimulation was given to the internal capsule to induce LTP (2 trains of 100 pulses delivered at $100 \mathrm{~Hz}, 20 \mathrm{~s}$ apart). As expected, we observed LTP in all P21 WT PNs with gbz (unpaired $t$ tests; Fig. 4A,B): EPSC charge integral [percent (\%) change, $\mathrm{MD} \pm \mathrm{SD}$ ], last $5 \mathrm{~min}_{\mathrm{WTgrp}}=$ $501.30 \pm 4.51 \%$, p pWTrp $<0.0001$, MD: $401.30 \% \mathrm{Cl}:$ [390.90, 411.70], $n_{\mathrm{WT}}=6$ neurons, 5 mice, $n=2$ FVB, 3 B6; EPSC charge integral ${ }_{W T 1}=468.43 \pm 51.21 \%, p_{\mathrm{WT} 1}<$ 0.0001, MD: $368.43 \%, \mathrm{Cl}:[315.41,421.71], n_{\mathrm{WT} 1}=1,1$; EPSC charge integral ${ }_{\text {WT2 }}=508.84 \pm 18.80 \%, p_{\text {WT2 }}<$ 0.0001, MD: 408.84, Cl: [387.00, 430.60]; $n_{\mathrm{WT2}}=1,1$; EPSC charge integral ${ }_{\mathrm{WT3}}=276.52 \pm 40.05 \%, p_{\mathrm{WT3}}<$ 0.0001 , MD: 176.52, Cl:[132.30, 220.80]; $n_{\mathrm{WT} 3}=1,1$, EPSC charge integral ${ }_{\mathrm{WT} 4}=140.30 \pm 2.29 \%, p_{\mathrm{WT} 4}<$ 0.0001 , MD: 40.30 , Cl:[36.13, 44.46]; $n_{\mathrm{WT} 4}=1$, 1; EPSC 

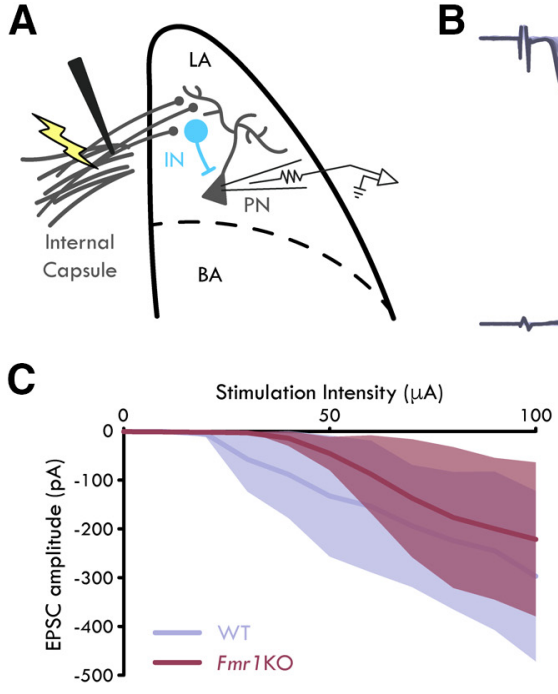

G

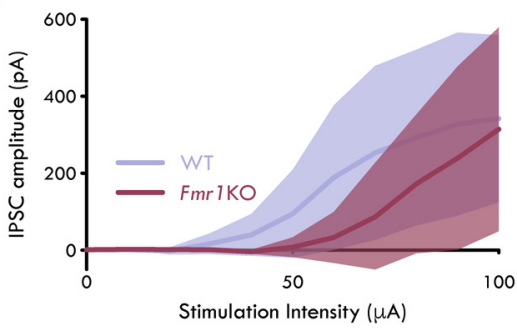

B
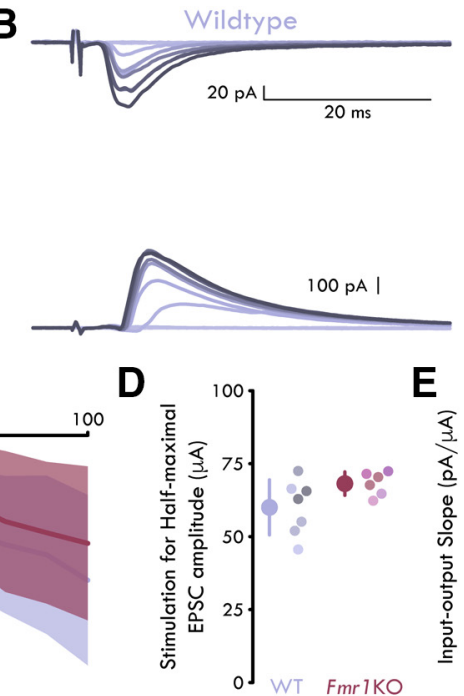

$\mathrm{H}$

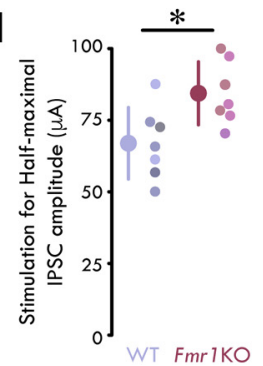

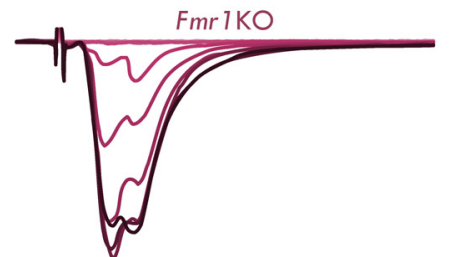
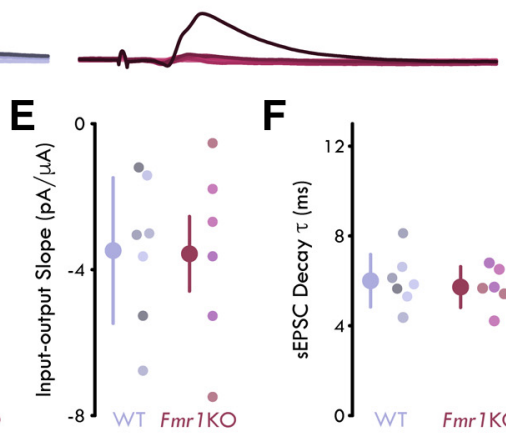

$\mathbf{F}$
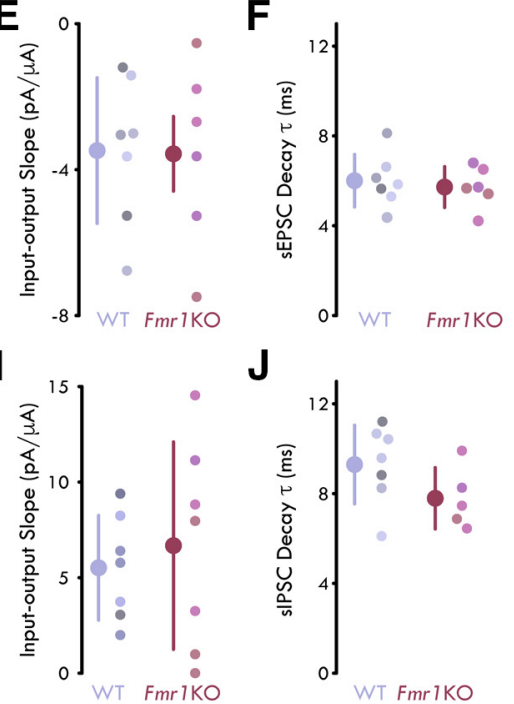

$\mathrm{J}$

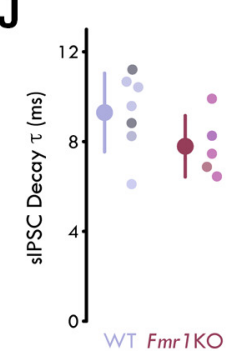

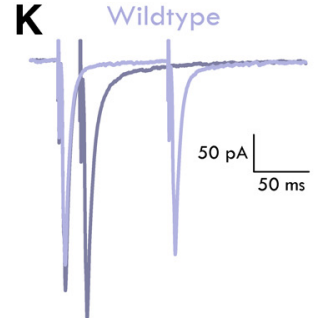

$\mathrm{Fmr} 7 \mathrm{KO}$
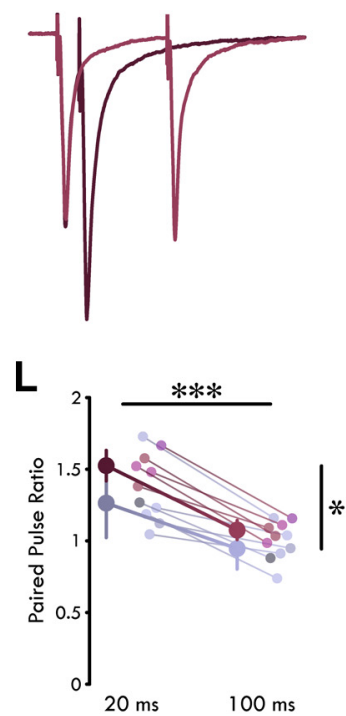

Figure 3. Reduced FFI in Fmr1KO LA. A, Experimental schematic. B, Representative mean traces of EPSCs (top) and IPSCs (bottom) in LA PNs following internal capsule stimulation. Color scales with stimulation intensity (light to dark: $0-100 \mu A)$. C, Mean evoked EPSC amplitude as a function of stimulation intensity. Shading shows SD. $\boldsymbol{D}$, Stimulation for half-maximal EPSC amplitude is not significantly different for LA PNs from WT and Fmr1KO mice [unpaired $t$ test: $p=0.0754 ; n_{\mathrm{WT}}=7$ neurons, 5 mice, 5 males (M); $n_{F m r 1 \mathrm{KO}}=6,3,3 \mathrm{M}$. $E$, Evoked EPSC input-output slope is not significantly different for LA PNs from WT and Fmr1KO mice (unpaired $t$ test: $p=0.944 ; n_{\mathrm{WT}}=7$ neurons, 5 mice, $\left.5 \mathrm{M} ; n_{F m r 1 \mathrm{KO}}=6,3,3 \mathrm{M}\right)$. $\boldsymbol{F}$, Evoked EPSC decay $\tau$ is not significantly different for LA PNs from WT and Fmr1KO mice (unpaired $t$ test: $p=0.641 ; n_{\mathrm{WT}}=7,5,5 \mathrm{M} ; n_{\text {Fmr1KO }}=6,3,3 \mathrm{M}$ ). G, Mean evoked IPSC amplitude as a function of stimulation intensity. Shading shows SD. $\boldsymbol{H}$, Stimulation for half-maximal IPSC amplitude is increased for LA PNs from Fmr1KO mice (unpaired $t$ test: $p=0.0168 ; n_{\mathrm{WT}}=7,4,4 \mathrm{M} ; n_{F m r 1 \mathrm{KO}}=7,3,3 \mathrm{M}$ ). I, Evoked IPSC input-output slope is not significantly different for LA PNs from WT and Fmr1KO mice (unpaired $t$ test: $p=0.623 ; n_{\mathrm{WT}}=7,4,4 \mathrm{M} ; n_{\text {Fmr1KO }}=7,3,3 \mathrm{M}$ ). J, Evoked IPSC decay $\tau$ is not significantly different for LA PNs from WT and Fmr1KO mice (unpaired $t$ test: $p=0.141 ; n_{\mathrm{WT}}=7,5,5 \mathrm{M}$; $\left.n_{\text {Fmr1KO }}=5,3,3 \mathrm{M}\right) . \boldsymbol{K}$, Representative mean traces of EPSCs in paired-pulse experiments. Darker colors show 20-ms interstimulus interval, and lighter colors show $100-\mathrm{ms}$ interstimulus interval. $L$, Paired-pulse ratio is increased in PNs from Fmr1KO mice and for shorter interstimulus interval durations (two-way repeated measures ANOVA, main effects of genotype and interstimulus interval: $\left.p_{\text {Genotype }}=0.0465, p_{\text {interstimulus interval }}=1.56 \times 10^{-5} ; n_{\mathrm{WT}}=6,4,4 \mathrm{M} ; n_{F m r 1 \mathrm{KO}}=5,3,3 \mathrm{M}\right)$. All summary statistics as mean $\pm \mathrm{SD}$; ${ }^{\star} p<0.05,{ }^{\star \star \star} p<0.001$. Individual neurons plotted and represented by different colors on a per animal basis.

charge integral ${ }_{\mathrm{WT} 5}=1508.00 \pm 19.16 \%, p_{\mathrm{WT} 5}<0.0001$ MD: $1408.00, \mathrm{Cl}:[1388.00,1428.00] ; n_{\mathrm{WT} 5}=1$, 1 ; EPSC charge integral $\mathrm{WTC}_{\mathrm{WT}}=105.80 \pm 1.40 \%, p_{\mathrm{WT}}=0.0003$, MD: $5.80, \mathrm{Cl}:[3.55,8.04] ; n_{\mathrm{WT} 6}=1,1$ (for how plasticity was determined, see Materials and Methods). Similarly, we observed LTP in all P21 Fmr1KO PNs with gbz (unpaired $t$ tests; Fig. $4 A, B)$ : EPSC charge integral, last 5 $\min _{\text {Fmr1KOgrp }} 178.20 \pm 9.69 \%, p_{\text {Fmr1KOgrp }}<0.0001$, MD: $78.20 \%$, Cl: $[55.85,100.57], n_{\text {Fmr } 1 \mathrm{KO}}=4,4 ; n=4 \mathrm{~B} 6$; EPSC charge integral ${ }_{\mathrm{Fmr} 1 \mathrm{KO} 1}=114.78 \pm 3.82 \%$, $p_{\text {Fmr1KO1 }}=0.0001, \mathrm{MD}: 14.78 \%, \mathrm{Cl}:[9.88,19.66]$, $n_{\text {Fmr1KO1 }}=1$, 1; EPSC charge integral ${ }_{F m r 1 K O 2}=122.25$ $\pm 6.50 \%, p_{\mathrm{Fmr} 1 \mathrm{KO} 2}=0.0002, \mathrm{MD}: 22.3 \%$, Cl: [14.58, 29.92], $n_{F_{\text {mr1 KO2 }}}=1$, 1; EPSC charge integral ${ }_{\mathrm{Fmr1KO} 3}=$ $313.9 \pm 93.6 \%, p_{\mathrm{Fmr} 1 \mathrm{KO} 3}=0.0009, \mathrm{MD}: 213.9 \%, \mathrm{Cl}:$ $[117.30,310.50], n_{\text {Fmr1KO3 }}=1$, 1; EPSC charge integral ${ }_{\mathrm{Fmr} 1 \mathrm{KO} 4}=161.90 \pm 2.95 \%, p_{\mathrm{Fmr} 1 \mathrm{KO} 4}<0.0001$, MD: $61.90 \%$, Cl: $[51.38,72.43], n_{F m r 1 \mathrm{KO} 4}=1$, 1 . However, in accordance with previous studies (Paradee et al., 1999; Zhao et al., 2005; Suvrathan et al., 2010), we observed a significant reduction in the magnitude of LTP in Fmr1KO PNs compared with WT LA PNs (unpaired $t$ tests: EPSC charge integral, last 5 min $_{\text {Fmr1KOvsWT, }} p_{\text {Fmr1KOvsWT }}<0.0001$, MD: 172.0, Cl: $[148.0,196.0], n_{\mathrm{WT}}=6$ neurons, 5 mice, $n_{\text {Fmr1KO }}=$ $4,4)$.

Under conditions in which local inhibition remained intact, we found that LA PNs as a group did not undergo LTP in slices from WT mice (unpaired $t$ tests; Fig. 4C,D): EPSC charge integral, last 5 min $_{\text {WTgrp }}=99.15 \pm 3.25 \%$, $p_{\text {WTgrp }}=0.80$, MD: $-0.84 \% \mathrm{Cl}:[-8.35,6.65], n_{\text {WTgrp }}=6$, $5, n=2 \mathrm{FVB}, n=3 \mathrm{~B} 6$, EPSC charge integral $\mathrm{WT}_{\mathrm{W} 1}=94.52 \pm$ $5.07 \%, p_{\mathrm{WT} 1}=0.39$, MD: $-5.48 \% \mathrm{Cl}:[-19.26,8.30], n_{\mathrm{WT} 1}$ 


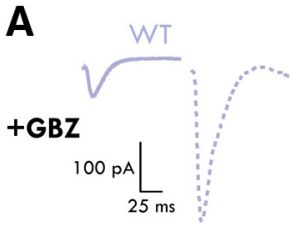

B

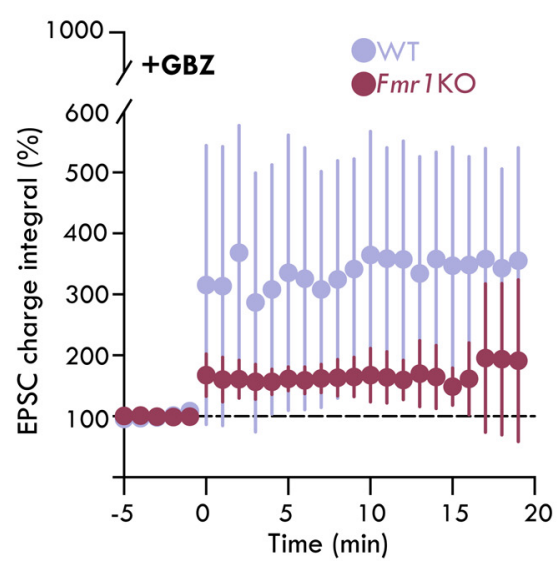

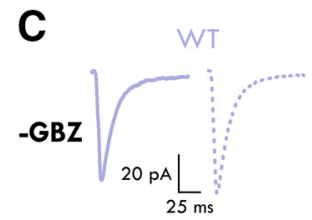

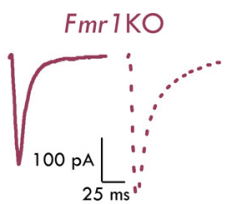

D

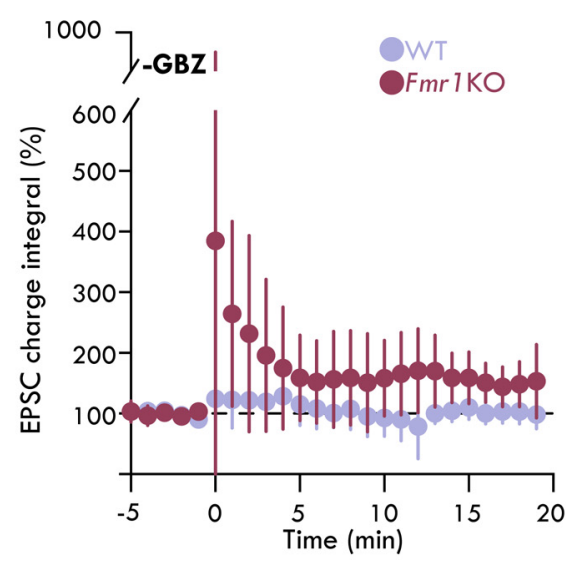

Figure 4. Aberrant LTP in Fmr1KO LA. A, Representative mean EPSCs from LA PNs with $10 \mu \mathrm{m}$ gbz. Solid lines show mean EPSCs before LTP induction and dashed lines show EPSCs at end of experiment. $\boldsymbol{B}$, Normalized EPSC charge integral across LTP experiments with $10 \mu \mathrm{ms} \mathrm{gbz}$. All PNs underwent significant LTP in both WT and Fmr1KO LA [unpaired $t$ tests: $p_{\mathrm{WT} 1-6}<0.0001, p_{F m r 1 \mathrm{KO} 1}$ $<0.0001, p_{\text {Fmr1KO2 }}=0.000200, p_{\text {Fmr } 1 \mathrm{KO} 3}=0.000900, p_{\text {Fmr1KO4 }}<0.0001 ; n_{\mathrm{WT}}=6$ neurons, 5 mice, 4 males $(\mathrm{M}), 1$ female $(\mathrm{F})$; $n_{\text {Fmr1KO }}=4,4,2$ M, 2 F]. C, Representative mean EPSCs from LA PNs without gbz. Solid lines show mean EPSCs before LTP induction and dashed lines show EPSCs at end of experiment. $\boldsymbol{D}$, Normalized EPSC charge integral across LTP experiments without gbz. One of six PNs underwent significant LTP, 2 PNs underwent LTD, four did not undergo significant LTP or LTD in WT LA. All PNs underwent LTP in Fmr1KO LA (unpaired $t$ tests: $p_{\mathrm{WT} 1}=0.386, p_{\mathrm{WT} 2}=0.142, p_{\mathrm{WT} 3}=0.989, p_{\mathrm{WT} 4}=0.0019, p_{\mathrm{WT} 5}=0.0123, p_{\mathrm{WT} 6}$ $\left.<0.0001 . p_{F m r 1 \mathrm{KO} 1}=0.00540, p_{\text {Fmr1KO2-5}}<0.0001 ; n_{\mathrm{WT}}=6,4,3 \mathrm{M}, 1 \mathrm{~F} ; n_{\mathrm{Fmr} 1 \mathrm{KO}}=5,3,2 \mathrm{M}, 1 \mathrm{~F}\right)$. Summary statistics presented as mean \pm SD.

$=1,1 ;$ EPSC charge integral ${ }_{\mathrm{WT} 2}=114.04 \pm 8.81 \%, \mathrm{MD}:$ $14.04 \% \mathrm{Cl}:[-5.81,33.89], p_{\mathrm{WT2}}=0.14, n_{\mathrm{WT2}}=1,1 ;$ EPSC charge integral ${ }_{\mathrm{WT} 3}=100.15 \pm 16.84 \%$, MD: $0.15 \% \mathrm{Cl}$ : $[-22.99,23.28], p_{\mathrm{WT} 3}=0.99, n_{\mathrm{WT} 3}=1$, 1 ; EPSC charge integral $_{\text {WT4 }}=119.84 \pm 3.08 \%, p_{\text {WT4 }}=0.0019, \mathrm{MD}$ : $19.84 \%$ Cl: $[9.72,29.95], n_{\text {WT } 4}=1$, 1 ; EPSC charge integral $_{\mathrm{WT} 5}=95.72 \pm 2.22 \%, \mathrm{MD}:-4.27 \% \mathrm{Cl}:[-7.34$, -1.21], $p_{\text {WT5 }}=0.0123, n_{\text {WT5 }}=1$, 1 ; EPSC charge integral ${ }_{\text {WT6 }}=70.65 \pm 1.12 \%, \mathrm{MD}:-29.35 \% \mathrm{Cl}$ : $[-35.79$, $-22.92], p_{\mathrm{WT} 6}<0.0001, n_{\mathrm{WT} 6}=1,1$. Interestingly, when we performed the same experiments in slices from Fmr1KO mice, we found that all neurons underwent significant LTP following high-frequency stimulation of thalamic afferents (unpaired $t$ tests; Fig. $4 C, D$ ): EPSC charge integral, last $5 \mathrm{~min}_{\mathrm{Fmr1KOgrp}}=151.30 \pm 2.96 \%, p_{\text {Fmr1KOgrp }}<0.0001$, MD: $51.30 \%$, Cl: [44.45, 58.11], $n_{\text {Fmr } 1 \text { KOgrp }}=5,3 ; n=1 \mathrm{FVB}$, $n=2$ B6; EPSC charge integral ${ }_{\mathrm{Fmr1KO}}=139.41 \pm 13.0 \%$, $p_{\text {Fmr1KO1 }}=0.00540, \mathrm{MD}: 39.41 \%, \quad \mathrm{Cl}:[15.36,63.46]$, $n_{F m r 1 \mathrm{KO} 1}=1$, 1; EPSC charge integral ${ }_{\mathrm{Fmr1KO} 2}=223.90 \pm$ $24.59 \%, p_{\text {Fmr } 1 \mathrm{KO} 2}=<0.0001$, MD: $123.90 \%$, Cl:[94.20, 153.60], $n_{\text {Fmr1KO2 }}=1$, 1; EPSC charge integral $\left.\right|_{\mathrm{Fr} 1 \mathrm{KO} 3}=$ $126.55 \pm 2.06 \%, p_{\text {Fmr1KO3 }}=0.0022, \mathrm{MD}: 26.55 \%$, Cl: $[12.76,40.33], n_{\text {Fmr1KO3 }}=1,1$; EPSC charge integral ${ }_{\mathrm{Fmr1KO} 4}=$ $129.70 \pm 3.34 \%, p_{\text {Fmr1KO4 }}<0.0001, \mathrm{MD}: 29.70 \%$, Cl:[24.40, 34.96], $n_{\mathrm{Fmr1KO4}}=1$, 1; EPSC charge integral ${ }_{\mathrm{Fmr1KO5}}=$ $136.90 \pm 8.23 \%, p_{\text {Fmr1KO5 }}<0.0001, \mathrm{MD}: 36.86 \%$, Cl: [27.49, 46.23], $n_{\text {Fmr1KO5 }}=1$, 1. Intriguingly, in $+\mathrm{gbz}$ condition, the magnitude of LTP in LA PNs in the Fmr1KO mouse exhibited only a modest increase (unpaired $t$ tests; Fig. $4 B, D$ ): EPSC charge integral, last 5 min $_{\text {Fmr1KO_GbzvsFmr1KO_noGbz, }}$ P Fmr1KO_GbzvsFmr1KO_noGbz $=$ $0.027, n_{\text {Fmr1KO_Gbz }}=4,4, n_{\text {Fmr1KO_noGbz }}=5$, 3. Thus, the reduced FFI onto LA PNs in Fmr1KO mice correlated with a lower threshold of synaptic plasticity induction and a reduced magnitude of LTP in an important circuit for classical sensory-threat conditioning.

\section{Discussion}

Synaptic dysfunction is a core aspect of NDDs (Chao et al., 2010; Zoghbi and Bear, 2012). In the present study, we investigated circuit function in a brain region known for reduced inhibitory neurotransmission in the Fmr1KO mouse model of FXS. Here, we show that PNs within the LA of Fmr1KO mice exhibit intrinsic membrane hyperexcitability over the P21-P35 developmental time point. Further, we show alterations in spontaneous and sensory afferent evoked excitatory and inhibitory neurotransmission. In particular, we demonstrate a preferential reduction in FFI onto PNs in the Fmr1KO LA. Finally, we find that the loss of FFI onto PNs and the increase in their excitability correlate with an enhancement of LTP at sensory afferents to the LA of Fmr1KO mice. Thus, we show coordinated changes in physiology, circuit function, and 
synaptic plasticity in a neural circuit responsible for sensory-threat learning.

\section{Increased excitability in LA may contribute to adverse behavioral symptoms in FXS}

Within the LA, activity-dependent excitation of PNs underlies associative threat learning (Repa et al., 2001; Rosenkranz and Grace, 2002; Duvarci and Pare, 2014; Wolff et al., 2014). For instance, onset of the conditioned stimulus (CS) during classical Pavlovian threat conditioning elicits strong excitation of projection PNs. Increases in CS-evoked spike activity are observed in LA PNs after training (Quirk et al., 1995; Schoenbaum et al., 1999). Further, threat conditioning results in enhanced excitatory synaptic transmission of the auditory thalamic afferents onto PNs of the LA (McKernan and Shinnick-Gallagher, 1997; Namburi et al., 2015), and input-specific, Hebbianlike LTP underlies this synaptic strengthening (Nabavi et al., 2014; Kim and Cho, 2017).

Hyperexcitable PNs and the LA have been postulated to underpin a number of the neurologic and psychiatric symptoms in FXS and ASDs, as well as other neuropsychiatric disorders, including posttraumatic stress and anxiety disorders, attention-deficit/hyperactivity disorder, and substance use disorders (Posner et al., 2011; Contractor et al., 2015; Sharp, 2017). However, to date, few studies have focused on the amygdala of FXS patients in early life. Here, we demonstrate that PNs in the Fmr1KO LA exhibit marked hyperexcitability compared with WT. Specifically, LA PNs show increased maximum firing rates, a lower rheobase, and a more depolarized $V_{\text {rest. }}$ Thus, LA PN hyperexcitability may contribute to the clinical symptomatology of FXS. Previous studies in the hippocampus and across cortex identified similar hyperexcitable phenotypes in excitatory neurons of Fmr1KO mice resulting from alterations in $\mathrm{HCN}$ and voltage-gated $\mathrm{Na}^{+}$and $\mathrm{K}^{+}$ion channels (Gu et al., 2007; Higgs and Spain, 2011; Gonçalves et al., 2013; Zhang et al., 2014; Kalmbach et al., 2015; Deng and Klyachko, 2016; Routh et al., 2017). To our knowledge, similar detailed ion channel studies have not been performed in the LA of Fmr1KO mice. Thus, whether these channelopathies are regionspecific or are also present in the LA of Fmr1KO mice remains to be determined. Future studies will be needed to completely define the ionic mechanisms underlying intrinsic excitability in PNs in the LA (Pape and Pare, 2010; Duvarci and Pare, 2014). Importantly, these studies may reveal new therapeutic targets for the treatment of anxiety disorders in FXS, ASDs, or other neuropsychiatric disorders.

\section{Alterations in inhibitory and excitatory synaptic strength underpin $\mathrm{E} / \mathrm{l}$ imbalance}

Globally, synaptic strength is modulated to maintain balanced excitatory and inhibitory activity within a network (Turrigiano, 1999). This synaptic scaling functions to maintain synaptic input in an activity-dependent manner (Turrigiano et al., 1998; Kilman et al., 2002). Our previous work has identified reductions in inhibitory synaptic efficiency and significant depletions in inhibitory function in PNs of Fmr1KO mice (Olmos-Serrano et al., 2010; Vislay et al., 2013; Martin et al., 2014) during P21-P30. Here, we extend these findings to include an enhancement of sEPSC amplitude in PNs in Fmr1KO LA. Taken together, these data suggest a circuit phenotype of enhanced excitability.

Additionally, we identified alterations in sIPSC decay kinetics and an enhancement of the frequency of sIPSCs onto local PNs. Previous work from our group identified alterations in GAT1-mediated GABA reuptake as well as $G A B A_{A} R$ subunit-selective pharmacology demonstrating that $G A B A_{A} R$-dependent and independent mechanisms underlie changes in SIPSC kinetics at this time point (Vislay et al., 2013). Further, changes in sIPSC frequency and amplitude have been shown to result from AP-dependent increases in network activity (Vislay et al., 2013). While the precise receptor (or non-receptor) mechanisms underpinning the excitatory synaptic changes observed in our study remain to be determined, given the hyperexcitable phenotype of LA PNs in the Fmr1KO mouse it stands to reason that SEPSC amplitudes may be altered in an AP-dependent manner. Similarly, changes in SEPSC decay kinetics implicate receptor subunit compositions any of which may be altered in Fmr1KO mice (Li et al., 2002; Guo et al., 2015; Cheng et al., 2017). However, we cannot rule out changes in cell geometry or distribution of synapses. Future anatomic and biophysical studies will be needed to address potential sources of synaptic dysfunction. Interestingly, we did not observe similar changes in the decay kinetics of evoked responses. This may be because of the inherent mechanistic differences that underlie evoked versus spontaneous events. Primarily, evoked responses release increased concentrations of neurotransmitter at the synaptic cleft, engage different mechanisms of diffusion and re-uptake, and potentially engage extra-synaptic receptors (Thompson and Gähwiler, 1992; Draguhn and Heinemann, 1996). Further, alterations in synaptic currents may result from differences in synaptic structure, postsynaptic receptor composition and intrinsic conductances. As many of these mechanisms are affected in FXS (D'Hulst et al., 2009; Adusei et al., 2010; OlmosSerrano et al., 2010), it is likely that changes in synaptic decay kinetics are masked in an evoked response as it is difficult to view a particular mechanism in isolation.

Unlike our previous studies with full excitatory synapse blockade (Olmos-Serrano et al., 2010; Vislay et al., 2013; Martin et al., 2014), in these studies, we used recording conditions that would enable the evaluation of both excitatory and inhibitory synaptic neurotransmission within the same cell. To do this, we filled pipettes with a CsMe intracellular solution which reduces resting and leak conductances and improves space-clamp. While imperfect, this method is superior to potassium-based internals for the measurement of more distal dendritic synapses that would normally be filtered (Williams and Mitchell, 2008). Thus, our synaptic recordings may have enabled better voltage control at more distal synapses, allowing us to evaluate additional sites of excitation and inhibition. 
We speculate two possibilities for the role of enhancement of spontaneous, presynaptic inhibitory activity. First, it may function to compensate broadly for postsynaptic modulation of excitatory neurotransmission in a multiplicative manner (Turrigiano and Nelson, 2004) to maintain circuit homeostasis. Consistent with this, the magnitude of sEPSC amplitudes was increased in Fmr1KO LA PNs. Thus, increased sIPSC frequency may represent a compensatory homeostatic mechanism underlying gain control in the LA of Fmr1KO mice.

Alternatively, enhancement of spontaneous, presynaptic inhibitory activity may represent a homeostatic response to depleted FFI. FFI gates plasticity in the BLA circuit underlying learning of the sensory-threat associations (Bissière et al., 2003; Tully et al., 2007; Wolff et al., 2014; Bazelot et al., 2015). Importantly, disruption of this plasticity is believed to underlie the major pathophysiology of mood disorders such as anxiety and stress disorders (Duvarci and Pare, 2014). Our data reveal that at P21, evoked $\mathrm{FFI}$ is reduced in Fmr1KOs while evoked excitation is largely unaffected. Our results are in accordance with a recent study evaluating $\mathrm{E} / \mathrm{I}$ conductance in the somatosensory cortex in the Fmr1KO mouse. In this study, a similar reduction in $\mathrm{FFI}$ in the $\mathrm{L} 4 \rightarrow \mathrm{L} 2 / 3$ feedforward circuit was observed coupled with a weaker decrease in feedforward excitation. Computational modeling using a parallel conductance model suggested that the overall net effect of this increase in E/I ratio was to maintain circuit homeostasis (Antoine et al., 2019). Thus, the increase in spontaneous inhibitory neurotransmission may represent a homeostatic mechanism to compensate for a loss of FFI in the LA of the Fmr1KO mouse. However, other studies in the Fmr1KO somatosensory cortex have demonstrated similar synaptic alterations with concomitant reductions in experiencedependent plasticity (Bureau et al., 2008; Harlow et al., 2010). Future studies should address the idiosyncrasies of how loss of $F m r 1$ affects distinct neural circuits across the brain and their corresponding behaviors. Converging evidence from our group and others implicates LA Sst ${ }^{+}$INs in FFI gating of LTP (Smith et al., 2000; Bissière et al., 2003; Unal et al., 2014; Wolff et al., 2014; Ito et al., 2019; Guthman et al., 2020). However, it remains to be shown if specific alterations in $\mathrm{Sst}^{+}$IN function underlie the facilitated LTP seen in Frm1KO LA. Future studies will be needed to address IN function in a cell-type-specific manner in the Fmr1KO LA.

\section{$\mathrm{E} / \mathrm{l}$ imbalance drives aberrant plasticity in the in the Fmr1KO LA}

In our previously published work, we revealed that excitatory PNs in the Fmr1KO LA display a tendency toward narrower integration windows (Martin et al., 2014) that may imply decreased capacity for accurate input integration (Pouille and Scanziani, 2001; Isaacson and Scanziani, 2011) and plasticity in a circuit that is crucial for regulating fear and anxiety (Ehrlich et al., 2009). Indeed, numerous studies examining the neural correlates of amygdalabased behaviors in human FXS patients and mouse models have demonstrated reductions in amygdala function. In adolescents and adults with FXS, imaging studies conducted during the presentation of fearful stimuli demonstrated attenuated amygdala activation (Hessl et al., 2007, 2011; Kim et al., 2014). In the mouse model of FXS, previous studies of PNs in the LA of Fmr1KO mice have identified impairments in LTP (extracellular field recordings) in PNs in the LA (Paradee et al., 1999; Zhao et al., 2005; Suvrathan et al., 2010), reductions in the surfaceexpression of AMPA receptors (Suvrathan et al., 2010), and impairments in metabotropic glutamate receptor (mGluR)-mediated LTP, a process which modulates LTP in the LA under normal circumstances (Rodrigues et al., 2002). These plasticity deficits also occur in the context of presynaptic and postsynaptic deficits including reductions of both the frequency and amplitude of miniature excitatory postsynaptic currents and weakened excitatory presynapses (Suvrathan et al., 2010). However, these previous studies were conducted in older animals and employed LTP induction protocols in the presence of GABA $A_{A}$ receptor blockers. Thus, we could not directly compare these data to how the fluctuations of excitation and inhibition in the Fmr1KO mouse affects synaptic plasticity.

Since few studies have focused on emotional processing systems and how loss of the FMRP may affect circuit function and plasticity earlier in life, we evaluated LTP with and without $G A B A_{A}$ receptor blockers in younger animals to directly assess the inhibitory gating of synaptic plasticity in the juvenile LA of the Fmr1KO mouse. In accordance with the above-mentioned studies, under conditions of complete inhibitory blockade, we observed a reduction in the magnitude of LTP obtained in Fmr1KO LA PNs in the mouse compared with WT PNs suggesting that deficient plasticity emerges early in postnatal development. Most surprisingly, contrary to these reports of decreased synaptic plasticity in the LA of the Fmr1KO mice (Zhao et al., 2005), we observed that reduced FFI correlates with LTP in the thalamo-amygdalar circuit of juvenile Fmr1KO mice without inhibitory blockade. Thus, we postulate that lower threshold plasticity in the circuits responsible for fear-learning may underpin the pathophysiology of anxiety disorders in FXS and ASDs in early life. The mechanisms of fear extinction have been shown to be varied and complex (Myers and Davis, 2007). To the extent that fear extinction in the thalamo-amygdalar circuit is a process mediated by depotentiation (Kim et al., 2007; Hong et al., 2009), it is plausible that that loss of FMRP lowers the threshold for forming fear memories coupled with broad reductions in the efficacy of synaptic plasticity mechanisms underlying fear extinction. Thus, patients with FXS and ASD may be more prone to encode fear memories with a reduced ability to alter them. However, anxiety and fear-related disorders in FXS and ASDs may also be mediated by other mechanisms including changes in brain-wide functional connectivity (Haberl et al., 2015; Shen et al., 2016) or changes in neuromodulation (Hessl et al., 2002; Ghilan et al., 2015).

Of note, while both male and female animals were included in this study, male and female animals were not equally represented in our study populations which precluded rigorous sex difference analyses. Given the focus on sex as a biological variable, future studies examining 
sex differences are warranted. Regarding plasticity, future studies will be necessary to evaluate whether exogenously altering E/I balance, perhaps through the enhancement of inhibition, is capable of normalizing synaptic plasticity in the LA of the Fmr1 KO mouse. Additionally, studies focused on plasticity mechanisms and behavioral studies related to fear retention and extinction are warranted. Further, changes in synaptic plasticity and fearlearning throughout early development will be needed to determine whether the trajectory of plastic changes seen in the juvenile BLA of Fmr1 KO mice is pathologic or homeostatic.

\section{References}

Adusei DC, Pacey LK, Chen D, Hampson DR (2010) Early developmental alterations in GABAergic protein expression in fragile $\mathrm{X}$ knockout mice. Neuropharmacology 59:167-171.

Antoine MW, Langberg T, Schnepel P, Feldman DE (2019) Increased excitation-inhibition ratio stabilizes synapse and circuit excitability in four autism mouse models. Neuron 101:648-661.e4.

Baron-Cohen S, Ring HA, Bullmore ET, Wheelwright S, Ashwin C, Williams SCR (2000) The amygdala theory of autism. Neurosci Biobehav Rev 24:355-364.

Bauman ML, Kemper TL (2005) Neuroanatomic observations of the brain in autism: a review and future directions. Int J Dev Neurosci 23:183-187.

Bazelot M, Bocchio M, Kasugai Y, Fischer D, Dodson PD, Ferraguti F, Capogna M (2015) Hippocampal theta input to the amygdala shapes feedforward inhibition to gate heterosynaptic plasticity. Neuron 87:1290-1303.

Bissière S, Humeau Y, Lüthi A (2003) Dopamine gates LTP induction in lateral amygdala by suppressing feedforward inhibition. Nat Neurosci 6:587-592.

Bureau I, Shepherd GMG, Svoboda K (2008) Circuit and plasticity defects in the developing somatosensory cortex of Fmr1 knockout mice. J Neurosci 28:5178-5188.

Chao HT, Chen H, Samaco RC, Xue M, Chahrour M, Yoo J, Neul JL, Gong S, Lu HC, Heintz N, Ekker M, Rubenstein JLR, Noebels JL, Rosenmund C, Zoghbi HY (2010) Dysfunction in GABA signalling mediates autism-like stereotypies and Rett syndrome phenotypes. Nature 468:263-269.

Chen L, Yun SW, Seto J, Liu W, Toth M (2003) The fragile x mental retardation protein binds and regulates a novel class of mRNAs containing u rich target sequences. Neuroscience 120:1005-1017.

Cheng GR, Li XY, Xiang YD, Liu D, McClintock SM, Zeng Y (2017) The implication of AMPA receptor in synaptic plasticity impairment and intellectual disability in fragile $X$ syndrome. Physiol Res 66:715-727

Clifford S, Dissanayake C, Bui QM, Huggins R, Taylor AK, Loesch DZ (2007) Autism spectrum phenotype in males and females with fragile $X$ full mutation and premutation. J Autism Dev Disord 37:738-747.

Contractor A, Klyachko VA, Portera-Cailliau C (2015) Altered neuronal and circuit excitability in fragile $X$ syndrome. Neuron 87:699715.

Cordeiro L, Ballinger E, Hagerman R, HessI D (2011) Clinical assessment of DSM-IV anxiety disorders in fragile $X$ syndrome: prevalence and characterization. J Neurodev Disord 3:57-67.

Dalton KM, Nacewicz BM, Johnstone T, Schaefer HS, Gernsbacher MA, Goldsmith HH, Alexander AL, Davidson RJ (2005) Gaze fixation and the neural circuitry of face processing in autism. Nat Neurosci 8:519-526.

Darnell JC, Van Driesche SJ, Zhang C, Hung KYS, Mele A, Fraser CE, Stone EF, Chen C, Fak JJ, Chi SW, Licatalosi DD, Richter JD, Darnell RB (2011) FMRP stalls ribosomal translocation on mRNAs linked to synaptic function and autism. Cell 146:247-261.
Deng PY, Klyachko VA (2016) Increased persistent sodium current causes neuronal hyperexcitability in the entorhinal cortex of Fmr1 knockout mice. Cell Rep 16:3157-3166.

D'Hulst C, De Geest N, Reeve SP, Van Dam D, De Deyn PP, Hassan BA, Kooy RF (2006) Decreased expression of the GABAA receptor in fragile X syndrome. Brain Res 1121:238-245.

D'Hulst C, Heulens I, Brouwer JR, Willemsen R, De GN, Reeve SP, De Deyn PP, Hassan BA, Kooy RF (2009) Expression of the GABAergic system in animal models for fragile $X$ syndrome and fragile $X$ associated tremor/ataxia syndrome (FXTAS). Brain Res 1253:176-183.

Draguhn A, Heinemann U (1996) Different mechanisms regulate IPSC kinetics in early postnatal and juvenile hippocampal granule cells. J Neurophysiol 76:3983-3993.

Duvarci S, Pare D (2014) Amygdala microcircuits controlling learned fear. Neuron 82:966-980.

Ehrlich I, Humeau Y, Grenier F, Ciocchi S, Herry C, Lüthi A (2009) Amygdala inhibitory circuits and the control of fear memory. Neuron 62:757-771.

El Idrissi A, Ding XH, Scalia J, Trenkner E, Brown WT, Dobkin C (2005) Decreased GABA(A) receptor expression in the seizureprone fragile $X$ mouse. Neurosci Lett 377:141-146.

Fu YH, Kuhl DPA, Pizzuti A, Pieretti M, Sutcliffe JS, Richards S, Verkert AJMH, Holden JJA, Fenwick RG, Warren ST, Oostra BA, Nelson DL, Caskey CT (1991) Variation of the CGG repeat at the fragile $X$ site results in genetic instability: resolution of the Sherman paradox. Cell 67:1047-1058.

Ghilan M, Hryciw BN, Brocardo PS, Bostrom CA, Gil-Mohapel J, Christie BR (2015) Enhanced corticosteroid signaling alters synaptic plasticity in the dentate gyrus in mice lacking the fragile $X$ mental retardation protein. Neurobiol Dis 77:26-34.

Gibson JR, Bartley AF, Hays SA, Huber KM (2008) Imbalance of neocortical excitation and inhibition and altered UP states reflect network hyperexcitability in the mouse model of fragile $X$ syndrome. $J$ Neurophysiol 100:2615-2626.

Gonçalves JT, Anstey JE, Golshani P, Portera-Cailliau C (2013) Circuit level defects in the developing neocortex of fragile $\mathrm{X}$ mice. Nat Neurosci 16:903-909.

Grewe BF, Gründemann J, Kitch LJ, Lecoq JA, Parker JG, Marshall JD, Larkin MC, Jercog PE, Grenier F, Li JZ, Lüthi A, Schnitzer MJ (2017) Neural ensemble dynamics underlying a long-term associative memory. Nature 543:670-675.

Gu N, Vervaeke K, Storm JF (2007) BK potassium channels facilitate high-frequency firing and cause early spike frequency adaptation in rat CA1 hippocampal pyramidal cells. J Physiol 580:859-882.

Guo W, Polich ED, Su J, Gao Y, Christopher DM, Allan AM, Wang M, Wang F, Wang G, Zhao X (2015) Fragile X proteins FMRP and FXR2P control synaptic GluA1 expression and neuronal maturation via distinct mechanisms. Cell Rep 11:1651-1666.

Guthman EM, Garcia JD, Ma M, Chu P, Baca SM, Smith KR, Restrepo D, Huntsman MM (2020) Cell-type-specific control of basolateral amygdala neuronal circuits via entorhinal cortex-driven feedforward inhibition. Elife 9:e50601.

Haberl MG, Zerbi V, Veltien A, Ginger M, Heerschap A, Frick A (2015) Structural-functional connectivity deficits of neocortical circuits in the $\mathrm{Fmr} 1^{-1 /}$ mouse model of autism. Sci Adv 1:e1500775.

Hagerman RJ, Berry-Kravis E, Kaufmann WE, Ono MY, Tartaglia N, Lachiewicz A, Kronk R, Delahunty C, Hessl D, Visootsak J, Picker J, Gane L, Tranfaglia M (2009) Advances in the treatment of fragile X syndrome. Pediatrics 123:378-390.

Harlow EG, Till SM, Russell TA, Wijetunge LS, Kind P, Contractor A (2010) Critical period plasticity is disrupted in the barrel cortex of Fmr1 knockout mice. Neuron 65:385-398.

Hessl D, Glaser B, Dyer-Friedman J, Blasey C, Hastie T, Gunnar M, Reiss AL (2002) Cortisol and behavior in fragile $X$ syndrome. Psychoneuroendocrinology 27:855-872.

Hessl D, Rivera SM, Reiss AL (2004) The neuroanatomy and neuroendocrinology of fragile X syndrome. Ment Retard Dev Disabil Res Rev 10:17-24. 
Hessl D, Rivera S, Koldewyn K, Cordeiro L, Adams J, Tassone F, Hagerman PJ, Hagerman RJ (2007) Amygdala dysfunction in men with the fragile $X$ premutation. Brain 130:404-416.

HessI D, Wang JM, Schneider A, Koldewyn K, Le L, Iwahashi C, Cheung K, Tassone F, Hagerman PJ, Rivera SM (2011) Decreased fragile $\mathrm{X}$ mental retardation protein expression underlies amygdala dysfunction in carriers of the fragile $X$ premutation. Biol Psychiatry 70:859-865.

Higgs MH, Spain WJ (2011) Kv1 channels control spike threshold dynamics and spike timing in cortical pyramidal neurones: Kv1 channels control threshold dynamics. J Physiol 589:5125-5142.

Hong I, Song B, Lee S, Kim J, Kim J, Choi S (2009) Extinction of cued fear memory involves a distinct form of depotentiation at cortical input synapses onto the lateral amygdala. Eur $J$ Neurosci 30:2089-2099.

Huber KM, Gallagher SM, Warren ST, Bear MF (2002) Altered synaptic plasticity in a mouse model of fragile $X$ mental retardation. Proc Natl Acad Sci USA 99:7746-7750.

Isaacson JS, Scanziani M (2011) How inhibition shapes cortical activity. Neuron 72:231-243.

Ito W, Fusco B, Morozov A (2019) Disinhibition-assisted LTP in the prefrontal-amygdala pathway via suppression of somatostatin-expressing interneurons. bioRxiv 10.1101/799346.

Janak PH, Tye KM (2015) From circuits to behaviour in the amygdala. Nature 517:284-292.

Kalmbach BE, Johnston D, Brager DH (2015) Cell-type specific channelopathies in the prefrontal cortex of the fmr1-/y mouse model of fragile $X$ syndrome. eNeuro 2:ENEURO.0114-15.2015.

Kasugai Y, Vogel E, Hörtnagl H, Schönherr S, Paradiso E, Hauschild M, Göbel G, Milenkovic I, Peterschmitt Y, Tasan R, Sperk G, Shigemoto R, Sieghart W, Singewald N, Lüthi A, Ferraguti F (2019) Structural and functional remodeling of amygdala GABAergic synapses in associative fear learning. Neuron 104:781-794.e4.

Kilman V, van Rossum MCW, Turrigiano GG (2002) Activity deprivation reduces miniature IPSC amplitude by decreasing the number of postsynaptic $\mathrm{GABA}_{\mathrm{A}}$ receptors clustered at neocortical synapses. J Neurosci 22:1328-1337.

Kim J, Lee S, Park K, Hong I, Song B, Son G, Park H, Kim WR, Park E, Choe HK, Kim H, Lee C, Sun W, Kim K, Shin KS, Choi S (2007) Amygdala depotentiation and fear extinction. Proc Natl Acad Sci USA 104:20955-20960.

Kim SY, Burris J, Bassal F, Koldewyn K, Chattarji S, Tassone F, Hessl D, Rivera SM (2014) Fear-specific amygdala function in children and adolescents on the fragile $X$ spectrum: a dosage response of the FMR1 gene. Cereb Cortex 24:600-613.

Kim WB, Cho JH (2017) Encoding of discriminative fear memory by input-specific LTP in the amygdala. Neuron 95:1129-1146.e5.

LeDoux JE, Farb CR, Milner TA (1991) Ultrastructure and synaptic associations of auditory thalamo-amygdala projections in the rat. Exp Brain Res 85:577-586.

Li J, Pelletier MR, Perez VJ, Carlen PL (2002) Reduced cortical synaptic plasticity and GluR1 expression associated with fragile $X$ mental retardation protein deficiency. Mol Cell Neurosci 19:138151.

Li Y, Mathis A, Grewe BF, Osterhout JA, Ahanonu B, Schnitzer MJ, Murthy VN, Dulac C (2017) Neuronal representation of social information in the medial amygdala of awake behaving mice. Cell 171:1176-1190.e17.

Liu XS, Wu H, Krzisch M, Wu X, Graef J, Muffat J, Hnisz D, Li CH, Yuan B, Xu C, Li Y, Vershkov D, Cacace A, Young RA, Jaenisch R (2018) Rescue of fragile $X$ syndrome neurons by DNA methylation editing of the FMR1 gene. Cell 172:979-992.e6.

Martin BS, Corbin JG, Huntsman MM (2014) Deficient tonic GABAergic conductance and synaptic balance in the fragile $X$ syndrome amygdala. J Neurophysiol 112:890-902.

McDonald AJ (1984) Neuronal organization of the lateral and basolateral amygdaloid nuclei in the rat. J Comp Neurol 222:589-606.

McKernan MG, Shinnick-Gallagher P (1997) Fear conditioning induces a lasting potentiation of synaptic currents in vitro. Nature 390:607-611.
Meredith RM, Dawitz J, Kramvis I (2012) Sensitive time-windows for susceptibility in neurodevelopmental disorders. Trends Neurosci 35:335-344.

Musumeci SA, Hagerman RJ, Ferri R, Bosco P, Bernardina BD, Tassinari CA, Sarro GB, Elia M (1999) Epilepsy and EEG findings in males with fragile $X$ syndrome. Epilepsia 40:1092-1099.

Myers KM, Davis M (2007) Mechanisms of fear extinction. Mol Psychiatry 12:120-150.

Nabavi S, Fox R, Proulx CD, Lin JY, Tsien RY, Malinow R (2014) Engineering a memory with LTD and LTP. Nature 511:348-352.

Namburi P, Beyeler A, Yorozu S, Calhoon GG, Halbert SA, Wichmann R, Holden SS, Mertens KL, Anahtar M, Felix-Ortiz AC, Wickersham IR, Gray JM, Tye KM (2015) A circuit mechanism for differentiating positive and negative associations. Nature 520:675-678.

Nelson SB, Valakh V (2015) Excitatory/inhibitory balance and circuit homeostasis in autism spectrum disorders. Neuron 87:684-698.

Olmos-Serrano JL, Paluszkiewicz SM, Martin BS, Kaufmann WE, Corbin JG, Huntsman MM (2010) Defective GABAergic neurotransmission and pharmacological rescue of neuronal hyperexcitability in the amygdala in a mouse model of fragile $X$ syndrome. $J$ Neurosci 30:9929-9938.

Paluszkiewicz SM, Olmos-Serrano JL, Corbin JG, Huntsman MM (2011) Impaired inhibitory control of cortical synchronization in fragile X syndrome. J Neurophysiol 106:2264-2272.

Pape HC, Pare D (2010) Plastic synaptic networks of the amygdala for the acquisition, expression, and extinction of conditioned fear. Physiol Rev 90:419-463.

Paradee W, Melikian HE, Rasmussen DL, Kenneson A, Conn PJ, Warren ST (1999) Fragile X mouse: strain effects of knockout phenotype and evidence suggesting deficient amygdala function. Neuroscience 94:185-192.

Posner J, Nagel BJ, Maia TV, Mechling A, Oh M, Wang Z, Peterson BS (2011) Abnormal amygdalar activation and connectivity in adolescents with attention-deficit/hyperactivity disorder. J Am Acad Child Adolesc Psychiatry 50:828-837.e3.

Pouille F, Scanziani M (2001) Enforcement of temporal fidelity in pyramidal cells by somatic feed-forward inhibition. Science 293:1159-1163.

Quirk GJ, Repa JC, LeDoux JE (1995) Fear conditioning enhances short-latency auditory responses of lateral amygdala neurons: parallel recordings in the freely behaving rat. Neuron 15:1029-1039.

Repa JC, Muller J, Apergis J, Desrochers TM, Zhou Y, LeDoux JE (2001) Two different lateral amygdala cell populations contribute to the initiation and storage of memory. Nat Neurosci 4:724-731.

Roberts JE, Bailey DB, Mankowski J, Ford A, Sideris J, Weisenfeld LA, Heath TM, Golden RN (2009) Mood and anxiety disorders in females with the FMR1 premutation. Am J Med Genet B Neuropsychiatr Genet 150B:130-139.

Rodrigues SM, Bauer EP, Farb CR, Schafe GE, LeDoux JE (2002) The group I metabotropic glutamate receptor mGluR5 is required for fear memory formation and long-term potentiation in the lateral amygdala. J Neurosci 22:5219-5229.

Rogers SJ, Wehner EA, Hagerman R (2001) The behavioral phenotype in fragile $\mathrm{X}$ : symptoms of autism in very young children with fragile $X$ syndrome, idiopathic autism, and other developmental disorders. J Dev Behav Pediatr 22:409-417.

Rosenkranz JA, Grace AA (2002) Dopamine-mediated modulation of odour-evoked amygdala potentials during pavlovian conditioning. Nature 417:282-287.

Routh BN, Rathour RK, Baumgardner ME, Kalmbach BE, Johnston D, Brager DH (2017) Increased transient $\mathrm{Na}^{+}$conductance and action potential output in layer $2 / 3$ prefrontal cortex neurons of the $\mathrm{fmr}^{-1 / y}$ mouse. J Physiol 595:4431-4448.

Sah P, Faber ESL, Lopez De Armentia M, Power J (2003) The amygdaloid complex: anatomy and physiology. Physiol Rev 83:803834.

Schoenbaum G, Chiba AA, Gallagher M (1999) Neural encoding in orbitofrontal cortex and basolateral amygdala during olfactory discrimination learning. J Neurosci 19:1876-1884. 
Sharp BM (2017) Basolateral amygdala and stress-induced hyperexcitability affect motivated behaviors and addiction. Transl Psychiatry 7:e1194.

Shen MD, Li DD, Keown CL, Lee A, Johnson RT, Angkustsiri K, Rogers SJ, Müller R-A, Amaral DG, Nordahl CW (2016) Functional connectivity of the amygdala is disrupted in preschool-aged children with autism spectrum disorder. J Am Acad Child Adolesc Psychiatry 55:817-824.

Smith Y, Paré JF, Paré D (2000) Differential innervation of parvalbuminimmunoreactive interneurons of the basolateral amygdaloid complex by cortical and intrinsic inputs. J Comp Neurol 416:496-508.

Suvrathan A, Hoeffer CA, Wong H, Klann E, Chattarji S (2010) Characterization and reversal of synaptic defects in the amygdala in a mouse model of fragile X syndrome. Proc Natl Acad Sci USA 107:11591-11596.

Thompson SM, Gähwiler BH (1992) Effects of the GABA uptake inhibitor tiagabine on inhibitory synaptic potentials in rat hippocampal slice cultures. J Neurophysiol 67:1698-1701.

Tsiouris JA, Brown WT (2004) Neuropsychiatric symptoms of fragile $X$ syndrome: pathophysiology and pharmacotherapy. CNS Drugs 18:687-703

Tully K, Li Y, Tsvetkov E, Bolshakov VY (2007) Norepinephrine enables the induction of associative long-term potentiation at thalamo-amygdala synapses. Proc Natl Acad Sci USA 104:1414614150.

Turk J, Robbins I, Woodhead M (2005) Post-traumatic stress disorder in young people with intellectual disability. J Intellect Disabil Res 49:872-875.

Turrigiano GG (1999) Homeostatic plasticity in neuronal networks: the more things change, the more they stay the same. Trends Neurosci 22:221-227.
Turrigiano GG, Nelson SB (2004) Homeostatic plasticity in the developing nervous system. Nat Rev Neurosci 5:97-107.

Turrigiano GG, Leslie KR, Desai NS, Rutherford LC, Nelson SB (1998) Activity-dependent scaling of quantal amplitude in neocortical neurons. Nature 391:892-896.

Unal G, Paré JF, Smith Y, Paré D (2014) Cortical inputs innervate calbindin-immunoreactive interneurons of the rat basolateral amygdaloid complex. J Comp Neurol 522:1915-1928.

Vislay RL, Martin BS, Olmos-Serrano JL, Kratovac S, Nelson DL, Corbin JG, Huntsman MM (2013) Homeostatic responses fail to correct defective amygdala inhibitory circuit maturation in fragile $X$ syndrome. J Neurosci 33:7548-7558.

Williams SR, Mitchell SJ (2008) Direct measurement of somatic voltage clamp errors in central neurons. Nat Neurosci 11:790798.

Wolff SBE, Gründemann J, Tovote P, Krabbe S, Jacobson GA, Müller C, Herry C, Ehrlich I, Friedrich RW, Letzkus JJ, Lüthi A (2014) Amygdala interneuron subtypes control fear learning through disinhibition. Nature 509:453-458.

Zhang Y, Bonnan A, Bony G, Ferezou I, Pietropaolo S, Ginger M, Sans N, Rossier J, Oostra B, LeMasson G, Frick A (2014) Dendritic channelopathies contribute to neocortical and sensory hyperexcitability in Fmr1-/y mice. Nat Neurosci 17:1701-1709.

Zhao MG, Toyoda H, Ko SW, Ding HK, Wu LJ, Zhuo M (2005) Deficits in trace fear memory and long-term potentiation in a mouse model for fragile X syndrome. J Neurosci 25:7385-7392.

Zoghbi HY, Bear MF (2012) Synaptic dysfunction in neurodevelopmental disorders associated with autism and intellectual disabilities. Cold Spring Harb Perspect Biol 4:a009886a009886. 